\title{
ESTADO DE EMERGENCIA POR CORONAVIRUS COMO DERECHO DE EXCEPCIÓN EMERGENTE. ¿MUTACIÓN O REFORMA CONSTITUCIONAL?
}

\author{
SARA SIEIRA MUCIENTES \\ Letrada de las Cortes Generales
}

TRC, n. ${ }^{\circ} 48,2021$, pp. $463-493$

ISSN 1139-5583

\begin{abstract}
SUMARIO
I. La respuesta jurídica a la crisis del Coronavirus en el derecho comparado: ejecutivos fortalecidos, parlamentos debilitados. II. Las respuestas de los países de nuestro entorno: alteración del sistema de fuentes e intensa intervención en el ámbito de los derechos fundamentales. III. Países de la órbita del Common Law. IV. La praxis del estado de alarma como mutación constitucional hasta la STC de 14 de julio de 2021. V. La conveniente reforma constitucional. Reformas constitucionales con motivo de la pandemia. VI. Conclusiones.
\end{abstract}

\section{LA RESPUESTA JURÍDICA A LA CRISIS DEL CORONAVIRUS EN EL DERECHO COMPARADO: EJECUTIVOS FORTALECIDOS, PARLAMENTOS DEBILITADOS}

La emergencia de salud pública por coronavirus declarado pandemia mundial en 2020 ha desencadenado una crisis sanitaria, social y económica global sin precedentes, a la que los Estados han respondido jurídicamente, en síntesis, bien utilizando el derecho de excepción o bien la legislación ordinaria. Según la Comisión Europea para la Democracia a través del Derecho, más conocida como la Comisión de Venecia, órgano asesor del Consejo de Europa en asuntos constitucionales, durante la crisis del coronavirus en la primavera de 2020 nueve estados miembros de la Unión Europea declararon un estado de emergencia bajo las previsiones contenidas en sus constituciones: Bulgaria, la República Checa, Finlandia, Estonia, Hungría, Luxemburgo, Portugal, Rumanía y España. En dos de 
estos países el estado de emergencia se declaró por el parlamento (Bulgaria y Portugal) y en los siete restantes la declaración fue gubernamental.

Otros cinco Estados miembros de la Unión Europea han declarado el estado de emergencia bajo su legislación general: Francia, Alemania, Italia, Lituania y Eslovaquia, y ello, aunque su Constitución contenga previsiones detalladas para cubrir diversos tipos de estados de emergencia, lo que se explica por la remisión a precedentes en situaciones similares o para evitar la aplicación de mecanismos excesivamente represivos (Francia, Alemania, y Eslovaquia). En Francia, incluso, como más adelante se expondrá, la ley creó un estado de emergencia de salud (l'état d'urgence sanitaire) de nuevo cuño. En el caso de Italia se ha optado por una solución híbrida, consistente en una mezcla de medidas legales y de previsiones constitucionales.

Otra categoría de países, constituida por catorce Estados miembros, no han declarado un estado de emergencia de iure durante la crisis del Covid-19: Austria, Bélgica, Croacia, Chipre, Dinamarca, Grecia, Irlanda, Lituania, Malta, Países Bajos, Polonia, Eslovenia, Suecia y el Reino Unido. La mayoría de ellos recurrieron a la legislación ordinaria, sobre todo la especial en materia de salud pública. En esta categoría también existen países que poseen previsiones constitucionales específicas que regulan diversos tipos de estados de emergencia (Países Bajos, Polonia, Grecia, Eslovenia, Lituania, Chipre). Suecia, que aparece como un caso particular en este grupo, ha confiado mayoritariamente en «recomendaciones» más que en leyes, si bien este soft law se ha complementado mediante la modificación de ciertas leyes ad hoc. Otro caso particular es el Reino Unido en el que el gobierno requirió al parlamento para aprobar urgente legislación que permitiera poderes de emergencia durante la crisis del COVID-19 ${ }^{1}$.

Asimismo, dentro de este panorama general, para el propósito del presente trabajo es importante señalar que la Comisión de Venecia ha concluido que durante la crisis de la COVID-19 los parlamentos en los estados miembros parecen haber quedado relegados a un papel secundario. Sin perjuicio del cumplimiento formal (a veces, incluso, dificultado o imposibilitado) de sus funciones constitucionales de declaración y prórroga del estado de emergencia, junto con la posibilidad de afectar incluso a su contenido, allí donde existe (República Checa, España) y de aprobar nuevas leyes aplicables a la situación (Dinamarca, Irlanda), los parlamentos en muchos países se han encontrado desplazados en favor del papel directivo de los gobiernos, con justificación en la necesaria rapidez y mayores recursos que poseen los ejecutivos para introducir medidas de emergencia.

En este marco pueden identificarse tres grandes grupos de países: en primer lugar, aquellos en que los parlamentos han continuado su trabajo en condiciones normales, si bien alterando algunos de sus procedimientos (Austria, Croacia,

1 Comisión de Venecia, Informe «On the measures taken in the Eu Member States as a result of the Covid-19 crisis and their impact on democracy, the rule of law and fundamental rights», CDL-AD(2020)018. Adoptado en su 124 Sesión Plenaria (celebrada on-line) 8-9 Octubre 2020, pp. 9-14 
Dinamarca, Estonia, Francia, Hungría, Irlanda, Letonia, Lituania, Luxemburgo, Malta, Países Bajos, Portugal, Rumanía, Eslovenia, Eslovaquia, Suecia). En segundo lugar, se encuentra el grupo de países en que los parlamentos han suspendido su actividad legislativa ordinaria y se han centrado exclusivamente en el control de las medidas relativas a la crisis del COVID (Bulgaria, Grecia). Un tercer grupo lo integran los países en que el parlamento ha disminuido su papel mediante la técnica de activar comisiones existentes o crear algunas ad hoc para recibir semanalmente la información del gobierno durante la crisis del COVID19, en lugar de situar al parlamento en el centro del debate (Finlandia, Italia, España, Bélgica). En bastantes países, adicionalmente, para articular una gran variedad de aspectos de la respuesta normativa se ha recurrido a las técnicas del decreto-ley o de la delegación legislativa, que, como es sabido, suponen una participación del parlamento limitada y posterior. Finalmente, en orden a ser más eficientes, algunos gobiernos han creado estructuras paralelas al parlamento, aunque no totalmente excluyentes del mismo, articulándose así una generalizada respuesta tecnocrática, $\mathrm{y}$, con ello, prefiriéndose procedimientos informales (reuniones, etc.) que fortalecen el papel del gobierno a expensas del parlamento. Esto, efectivamente, relega el papel del parlamento a una mera función de comprobación o supervisión (si se quiere, de control) del trabajo del gobierno a través de comisiones más que de debates plenarios.

Finalmente, el grupo de países cuyos parlamentos han suspendido sus actividades por completo, traspasando casi completamente todos los poderes al gobierno (Chipre, República Checa)².

\section{LAS RESPUESTAS DE LOS PAÍSES DE NUESTRO ENTORNO: ALTERACIÓN DEL SISTEMA DE FUENTES E INTENSA INTERVENCIÓN EN EL ÁMBITO DE LOS DERECHOS FUNDAMENTALES}

Avanzando un paso más, es claro que la pandemia ha supuesto un reto que los ordenamientos se han visto obligados a resolver utilizando fórmulas que no podían encuadrase plenamente en las previsiones del derecho constitucional de excepción allí donde existe, lo que ha significado en un alejamiento de las previsiones constitucionales (mutación o quiebra) en dos frentes principales, a saber: alteración de los sistemas de fuentes del derecho e imposición de limitaciones particularmente intensas de los derechos fundamentales, que, han supuesto auténticas suspensiones

2 Comisión de Venecia, cit., p. 18. Para un análisis más detallado, Castella Andreu, J. M., «La Comisión de Venecia y los estado de emergencia: la necesaria preservación del estado de Derecho y la democracia constitucional durante la crisis del Covid-19», en Biglino Campos, P. y Durán Alba, J. F. (dirs.), «Los efectos horizontales de la Covid-19 sobre el sistema constitucional: estudios sobre la primera oleada», Fundación Giménez Abad, Zaragoza, 2021, pp. 437-464. 
de los mismos ${ }^{3}$, por vías extraconstitucionales, que posteriormente han quedado incorporadas a la narrativa política o jurídica, según los casos, bien por su pacífica práctica, incontestada en el control de constitucionalidad, o bien mediante una interpretación de los Tribunales Constitucionales, que ha servido de base, precisamente, cuando se ha dado, a la mencionada mutación o incluso quiebra constitucional $^{4}$. Adicionalmente, en algunos casos, se ha sumado la crítica por reducirse el margen de control que ha quedado al Parlamento sobre la duración y extensión de las medidas. Por otra parte, los Estados que no poseen un derecho constitucional de excepción, tampoco se han visto exentos de crítica, básicamente en los mismos frentes.

En Alemania ${ }^{5}$ la respuesta jurídica se ha articulado sobre la base de que el virus SARS Cov-2 no supone una amenaza para el orden constitucional y por tanto no puede ser declarado un estado de emergencia interna dentro de los estrechos márgenes del art. 91. Por otra parte, el artículo 35 — estado de necesidadúnicamente obliga a las autoridades federales y estatales a una simple «cooperación interadministrativa», es decir, habilita a una respuesta policial, y, si la amenaza se extiende a más de un Land, puede emplearse a las Fuerzas Armadas en «apoyo» de la policía. Sin embargo, pese a que el artículo 35 no cubre misiones armadas, las medidas adoptadas han incluido un despliegue general de las Fuerzas Armadas en todos los Länder, llevando a cabo su misión civil más larga desde su establecimiento en 1955. Así pues, desde el punto de vista jurídico, el estado de emergencia no juega un papel decisivo en la crisis del COVID, pues, como se ha dicho, el art. 91 está pensado para supuestos de amenaza al orden constitucional. Sin embargo, en la discusión pública sobre las respuestas de los diferentes Länder este concepto está en el debate con mucha frecuencia ${ }^{6}$. La insuficiencia de los preceptos constitucionales para hacer frente a esta situación se contempló, incluso,

3 Para un análisis detallado del concepto de suspensión, AlÁEz Corral, B., «El concepto de suspensión general de los derechos fundamentales», en López Guerra, L., y Espín Templado, E. (coords.), $L a$ defensa del Estado, Tirant lo Blanch, Valencia, 2004, pp. 233-245.

4 Para una perspectiva más amplia sobre esta cuestión, Villaverde MenÉndeZ, I., Reformar interpretando. La jurisdicción constitucional como poder de reforma constitucional, en Aláez Corral, B. (coord.), «Reforma constitucional y defensa de la democracia», Universidad de Oviedo y CEPC, Madrid, 2020, pp. 441-468.

5 El derecho constitucional alemán no existe realmente un estado de emergencia que pudiera dar cobertura a la pandemia, puesto que tanto la agresión armada «Spannungsfall» (art. 80a) como el estado de emergencia interno (art. 91) como el estado de defensa (art. 115a-115c) resultan únicamente aplicables en caso de amenaza al orden constitucional democrático interno o ataque armado. El «estado de necesidad» interno (art.35), de carácter neutro desde el punto de vista de la afectación del orden constitucional, no está previsto más que para catástrofes naturales o graves siniestros asimilables, y su ámbito de acción se limita al empleo de las Fuerzas y Cuerpos de Seguridad del Estado y de las Fuerzas Armadas para auxiliar al Land o territorio amenazado, sin que suponga poderes adicionales para el Ejecutivo ni limitación de derechos fundamentales. En concreto, el estado de emergencia interno (art. 91) puede únicamente declararse para prevenir un peligro inminente para la existencia del orden constitucional libre y democrático, sea de la Federación o de un Land.

6 La razón, como se ha apuntado anteriormente, podría estar en la influencia de la teología política de Carl Schmitt: Jürgensen, S. y Orlowski, F., «Critique and Crisis: The German Struggle with Pandemic Control Measures and the State of Emergency», VerfBlog, 2020/4/19. 
desde las más altas instancias políticas del país: el presidente Shäube sugirió una reforma de la Constitución para posibilitar un parlamento de emergencia (nuevo artículo 53 b) permitiendo sesiones parlamentarias virtuales, así como la reducción del quorum de votación de $50 \%$ al $25 \%$ y la creación de una «Comisión de emergencia» compuesta por representantes de los grupos parlamentarios. La reforma no se llevó a cabo, en cuanto a la dificultad de su tramitación durante la vigencia de la emergencia, y porque, además, tocaría el concepto de representación, al suponer, en definitiva, una vulneración de la prohibición del mandato imperativo, comportando, además, una restricción en las funciones del parlamento — aun queriendo servir, paradójicamente, a una mayor funcionalidad del mismo- ${ }^{7}$.

La repuesta a la crisis en Alemania, por tanto, hubo de darse desde el Parlamento, mediante una ley para la prevención y la lucha contra la infección (Infektionsschutzgesetz) de 20 de julio de 2000 modificada el 17 de marzo de 2020. Esta respuesta ha sido criticada ${ }^{8}$ por el incremento de los poderes del ejecutivo central (se ha hablado de auténtico «desempoderamiento parlamentario») y por la restricción sin precedentes de derechos fundamentales, aun sin llegar a apreciar un riesgo de quiebra de la democracia en la lucha contra la pandemia, pues subsiste el control judicial de la legalidad y proporcionalidad de las medidas impuestas, en un ámbito como el del federalismo alemán que es un contrapeso potente respecto de la excesiva centralización. Pero sí se observa, desde la crítica, la necesidad de una más apropiada cobertura jurídica de las restricciones de los derechos y la observancia de los procedimientos legales 9 . Por su parte, los críticos de los críticos ${ }^{10}$ argumentan que los efectos de la pandemia han sido y serán tan impredecibles que en ese contexto se justifica una ampliación de los poderes de los ejecutivos sin que ello suponga un riesgo real para la democracia.

La Infektionsschutzgesetz se ha utilizado para establecer las restricciones necesarias, ya que dota de flexibilidad suficiente, con recurso a la técnica de las cláusulas generales, para que sean los gobiernos de los Länder los actores principales en el establecimiento y subsiguiente levantamiento de las medidas de control de la pandemia, sin perjuicio del sistema de competencia compartida, reforzado por

7 Gatтi, A., «L'emergenza Covid-19 in Germania e Austria: un bilancio comparato», en L'emergenza sanitaria da COVID-19: una prospettiva di diritto comparato, a cura di TARCHI, R., Rivista del Gruppo di Pisa. Dibattito aperto sul dirito e la Giustizia Costituzionale-Quaderno, n. ${ }^{\circ}$ 1, p. 47.

8 Möllers, C., «Parlamentarische Selbstentmächtigung im Zeichen des Virus», VerfBlog, 2020/3/26. Lepsius, O., «Vom Niedergang grundrechtlicher Denkkategorien in der Corona-Pandemie», VerfBlog, 2020/4/06.

9 KIngreen, T., Whatever it takes? Der demokratische Rechtstaat in Zeiten von Corona», VarfBlog, 2020/3/20, habla de inconstitucionalidad de la modificación normativa por decretos legislativos sin que el Bundestag tenga posibilidad de impedirlo. Por su parte, Katzenmeier, C., «Grundrechte in Zeiten Corona», MedR (Institut fur Medizinrecht), n. 38 (2020) se ocupa de la crítica a las restricciones de los derechos.

10 Steinbach, A., «Krisenmanagement für Jurist_innen», VerfBlog, 2020/4/05. 
medio de una modificación legislativa aprobada a mediados del mes de marzo, que permite al Bundestag declarar una crisis epidémica de importancia nacional, y concentrar algunas competencias ${ }^{11}$ en el Ministro de Sanidad. Esta ley funciona, simultáneamente, como ley de autorización y como ley marco para la adopción por parte de los Länder de medidas normativas y ha previsto la obligación de adoptar un mecanismo de coordinación sobre la base de conferencias sectoriales. En su mayor parte, la respuesta a la crisis en Alemania se ha producido sobre la base de medidas acordadas entre la Federación y los Länder, si bien no necesariamente homogéneas, de manera que cada $L$ and ha sido el responsable de aplicar las medidas según normativa propia, generalmente plasmada en fuentes secundarias (reglamentos y actos administrativos). La limitación de derechos fundamentales en este contexto se ha realizado sobre la base de una ley de autorización (que desde el punto de vista de la reserva de ley se considera fundamento suficiente ${ }^{12}$ ), coordinada aunque no homogénea, según los diversos supuestos de hecho existentes en cada territorio, con relación a los principios de idoneidad, necesidad y proporcionalidad con la que la jurisdicción (incluido Karlsrühe) puede apreciar la validez de las mismas, y sobre la base de la autoridad científico-técnica que representa el «parecer de los expertos», fuente de auxilio a las decisiones de los Ejecutivos que en Alemana está fuertemente institucionalizada en el Robert Koch Institut ${ }^{13}$.

El § 28 de la ley (medidas de protección), prevé que la autoridad competente pueda adoptar medidas como el confinamiento (afectándose así a la libertad personal, libertad de elección de residencia) o la limitación de la libertad de circulación y desplazamiento o la prohibición de entrada en determinados espacios y la práctica de exámenes médicos que limitan el derecho a la integridad física. Una última cuestión de interés es que el art. 74.1.19 de la Ley Fundamental considera materia de legislación concurrente la adopción de medidas contra las enfermedades infecciosas. Esto supone que los Länder pueden legislar únicamente y en la medida en que la Federación no haya realizado la propia competencia legislativa (art. 72 GG). Pues bien, la Infektionsschutzgesetz prevé una centralización forzando en tal sentido las previsiones constitucionales, al imponer, excepcionalmente, una suerte de cláusula de prevalencia del derecho federal sobre el estatal: el nuevo $\S 5$ habilita al Ministro de Sanidad para producir normativa que suspenda, e incluso, derogue a la normativa (incluso la contenida en fuentes primarias) de los Länder.

La justicia constitucional alemana aún no se ha pronunciado respecto de las decisiones más importantes, como la relativa a la constitucionalidad de las restricciones de movilidad ${ }^{14}$.

13 Para una visión más amplia, Kölling, M., «Las instituciones democráticas y los derechos fundamentales en tiempos de Covid-19 en Alemania», en Biglino/Durán, op. cit., «Los efectos horizontales...», pp. 467-486.

14 Por el momento, a la espera de las sentencias finales, existen dos resoluciones recientes en las que se negaron medidas cautelares frente a restricciones de movilidad y otras medidas de lucha contra la pandemia 
En Francia la respuesta normativa tampoco se ha configurado sobre la base del derecho de excepción establecido en el sistema normativo francés ${ }^{15}$, sino que el legislador ha preferido emplear la vía consagrada por el Conseil constitutionnel ${ }^{16}$, de establecer un «nuevo» estado de urgencia por medio de la ley n. 2020-290, de 23 de marzo 2020, con la que se crea un estado de emergencia general a través de una modificación del Código de Salud Pública. La entrada en vigor de la citada ley supuso la vigencia del primer estado de urgencia sanitaria en la totalidad del territorio nacional, que fue prorrogado sucesivamente mediante las respectivas leyes hasta el 10 de julio. Puede ser declarado en todo o en parte del territorio del Estado, por el Consejo de Ministros, previa consulta con el Ministro de Sanidad (artículos 3131-12 y 13 del CSP) en caso de catástrofe sanitaria que suponga un peligro, por su naturaleza o gravedad, para la salud de la población. Se creó un Comité científico para rendir cuentas del estado de la catástrofe sanitaria, el estado del conocimiento científico y las medidas oportunas a adoptar, y sobre esta base se efectuarían las consiguientes declaraciones de emergencia y la adopción de las medidas, cuyo control corresponderá al parlamento. La prórroga del estado de urgencia sanitaria ha de disponerse necesariamente por ley, que fijará la duración determinada de las medidas, pudiendo, no obstante, el Consejo de Ministros disponer la finalización de dicho estado y de las medidas que comporta. La alteración del sistema de fuentes que, como seguidamente se expondrá, esta ley comporta, ha sido criticada por quien ha visto en ello una «carta blanca» ${ }^{17} \mathrm{o}$, al menos, una cierta voluntad de evitar el control parlamentario.

En cuanto a las facultades que se confieren a la autoridad administrativa, el Primer Ministro, el Ministro de Sanidad y los prefectos, están facultados para ordenar restricciones de las libertades que, en circunstancias normales, se habrían considerado ilegales. Así, el Primer Ministro puede, por decreto, limitar la libertad de movimientos, de empresa y de reunión, prohibiendo los desplazamientos fuera del hogar, requisar aquellos bienes y servicios necesarios para poner fin a la catástrofe sanitaria, así como medidas temporales de control de precios $^{18}$.

(impuestas, entre otras, por la Sección 28b (1) del Infektionsschutzgesetz): el Beschluss vom 5. Mai 2021 y el Beschluss vom 20. Mai 2021.

$15 \mathrm{Ni}$ el artículo 16 de la Constitución, (que confiere al presidente de la República poderes excepcionales), ni el estado de sitio (artículo 36), ni la ley del estado de emergencia (n.1955-385), utilizada en las crisis de 2005 y 2015, se han aplicado en esta ocasión.

16 Decisión n. 2015-527 QPC del 22 diciembre 2015, que en su n. 8 señala que la Constitución no excluye la posibilidad de que el legislador establezca una regulación para el estado de emergencia que asegure un adecuado balance entre la prevención de los atentados al orden público y el respecto a los derechos y libertades garantizados a los residentes en la República, incluyendo la libertad deambulatoria protegida por los artículos 2 y 4 de la Declaración de Derechos de 1789.

17 Gelblat, A. y Marguet, L., «État d'urgence sanitaire: la doctrine dans tous ses états?», La Revue des droits de l'bomme, 23 de abril de 2020, p. 8.

18 La ley de 23 de marzo de 2020 realiza una larga enumeración exhaustiva de estas últimas en el artículo L. 3131-15 del Código de la Salud Pública. Levade, A., «État d'urgence sanitaire: à nouveau péril, 
La ley ha recurrido, para conferir tan amplios poderes al ejecutivo, a la utilización de la técnica de la legislación delegada contenida en el artículo 38 de la Constitución, que permite al gobierno ser autorizado por el parlamento, dentro de determinados límites, a aprobar ordenanzas en Consejo de Ministros, previo informe del Consejo de Estado, las cuales pueden incidir en el campo de la reserva de ley, debiendo ser posteriormente ratificadas por el parlamento.

Como ha sucedido en otros países, además de las relativas al sistema de fuentes, las dudas más importantes de la doctrina se centran en las medidas restrictivas de derechos, en torno a la necesidad y proporcionalidad de la elección del enfoque de la «seguridad» bajo la justificación de la tutela de la salud pública ${ }^{19}$. Es el Consejo de Estado quien debe pronunciarse en caso de peligro para las libertades fundamentales como consecuencia de las medidas adoptadas por el ejecutivo $^{20}$, si bien cuando se ha dirigido vía requerimiento al ejecutivo lo ha hecho para pedirle que endureciera las medidas sanitarias ${ }^{21}$; y por lo que respecta a la garantía judicial, las críticas se han centrado en la dificultad del control real de los jueces, puesto que la emergencia sanitaria supuso la interrupción del funcionamiento ordinario del contencioso-administrativo ${ }^{22}$, añadiéndose la percepción de una ponderación en que el principio de proporcionalidad cede ante la lógica de la narrativa de la seguridad ${ }^{23}$ cuando las decisiones en este orden debieran estar exclusivamente basadas en el parecer del Haut Coinseil de la santé publique ${ }^{24}$.

Finalmente, decir que Consejo Constitucional, que no pudo pronunciarse en el marco de su competencia a priori, contra la ley de 23 de marzo de 2020, se ha pronunciado sobre las medidas excepcionales adoptadas en varias ocasiones en la resolución de los recursos previos a la promulgación de las leyes previstos por el art. 61 de la Constitución ${ }^{25}$, sin que exista a su juicio (sin perjuicio de decisiones

nouveau régime d'exception», La Semaine Juridique, n. ${ }^{\circ}$ 13, 2020, pp. 613-616; AlCARAz, H., «El estado de emergencia sanitaria en Francia», Revista Catalana de Dret Públic, n. ${ }^{\circ}$ especial, 2020, pp. 153-161.

19 Wachsmann, P., Les libertés et les mesures prises pour lutter contre la propagation du covid-19», Le Semain Juridique, 18 de mayo de 2020.

20 Análisis pormenorizado en Alcaraz, H., op. cit., p. 159. El Consejo de Estado ha sido criticado por ser excesivamente respetuoso con las decisiones del Gobierno, véase MATHIEU, B., «Los desafíos constitucionales ante la crisis de salud debido al coronavirus. Análisis de la situación en Francia», ArNALDo AlcuBILla, E., y Canosa Usera, R., El derecho constitucional ante el Covid-19, Wolters Kluwer, Madrid, 2020, p. 303.

21 Para un análisis más amplio, Alcaraz, H., «El estado de emergencia en Francia, ¿Elogio de la excepción?, en op. cit., «Los efectos horizontales de la Covid-19 sobre el sistema constitucional», pp. 523-543, concretamente, pp. 536-538.

22 AA.VV., «Covid-19. Mesures d'adaptation des procédures et délais de recours devant les juridictions administratives», GIDE, 15 de mayo de 2020.

23 Renard, S., «L'état d'urgence sanitaire: droit d'exception et exceptions au droit», Revue des Droits et Libertés Fondamentaux, n. ${ }^{\circ} 2020$, chron. 13: «dans un contexte épidémique, la proportionnalité cède rapidement le pas à l'efficacité dans une logique sécuritaire».

24 Gelblat, A. y Marguet, L., «État d'urgence sanitaire...», ibídem.

25 La Decisión 2020-799 DC, de 26 de marzo, se pronuncia sobre la Loi organique d'urgence pour faire face à l'épidémie de covid-19 (promulgada como Ley Orgánica 2020-365, de 30 de marzo, que completa a la primera ley declarativa del estado de emergencia de 23 de marzo). La Decisión 2020-800 DC, de 11 de 
correctivas en derechos concretos) quiebra de la Constitución en el planteamiento general de la respuesta en Francia, — pese a las críticas doctrinales que se han suscitado porque el Consejo no entendió vulnerado el procedimiento de aprobación que, contra lo que establece el art. 46.2 de la Constitución, se examinó y aprobó en el Senado al día siguiente de su presentación sin respetar el plazo mínimo de 15 días entre ambas fases - lo cual constituye, sin duda, una mutación, cuando no una quiebra de la Constitución, construyendo algo parecido a los «principios de un derecho constitucional jurisprudencial de excepción» ${ }^{26}$.

En Italia la constitución de 1948 no establece medidas para un estado de emergencia o la transferencia de poderes especiales a una institución específica en tiempos de crisis $^{27}$. Sobre la base del artículo 24 del Código de Protección Civil que prevé la declaración del estado de emergencia para todas aquellas emergencias, por causas naturales o humanas, que requieran una respuesta inmediata por un periodo limitado de tiempo, el 31 de enero de 2020 el Consejo de Ministros decidió declarar dicho estado por un periodo de seis meses, hasta el 8 de abril, que pudiera ser extendido a 12 meses y renovado únicamente una vez. Según la norma, el departamento de protección civil puede adoptar medidas con el consentimiento de las regiones y las provincias autónomas implicadas con sometimiento al

mayo, resuelve los recursos presentados por el Presidente de la República, el presidente del Senado, sesenta Senadores y sesenta Diputados contra la Ley prorogeant l'état d'urgence sanitaire et complétant ses dispositions (promulgada como 2020-546, de 11 de mayo); La Decisión no 2020-808 DC, de 13 de noviembre, resuelve el recurso previo (presentado por más de sesenta Senadores) sobre la Ley autorisant la prorogation de l'état d'urgence sanitaire et portant diverses mesures de gestion de la crise sanitaire (2020-1379, de 14 de noviembre). La Decisión 2021-819 DC, de 31 de mayo de 2021, resuelve el presentado por más de sesenta Diputados contra la Ley relative à la gestion de la sortie de crise sanitaire (2021-689, de 31 de mayo). El tribunal también se ha pronunciado sobre la constitucionalidad de algunas medidas en la resolución de cuestiones prioritarias de constitucionalidad. Por ejemplo: Decisiones 2020-849 y 2020-850, ambas de 17 de junio, sobre las medidas tomadas en relación con las elecciones municipales de 2020. Decisión 2020-846/847/848 QPC, de 26 de junio, relativa a las violaciones reiteradas del confinamiento. Decisión 2020-851/852 QPC, de 3 de julio, sobre la constitucionalidad de la habilitación al Gobierno para prolongar la duración de las detenciones preventivas en el contexto del estado de urgencia sanitaria realizada por la Ley 2020-290, de 23 de marzo de 2020. Decisión 2020-866 QPC, de 19 de noviembre, sobre el establecimiento de un proceso civil sin audiencia en el contexto del estado de urgencia sanitaria.

26 MagnON, X., «Les principes d'un droit constitutionnel jurisprudentiel d'exception», L'Actualité juridique. Droit administratif, n. ${ }^{\circ} 23,2020$, p. 1257.

27 Aunque el artículo 78 de la Constitución italiana recoge el estado de guerra con la atribución de los poderes necesarios al gobierno, esta previsión no puede aplicarse aquellas situaciones que no tengan que ver con un conflicto armado. Sin embargo, el sistema legal italiano permite medidas especiales en circunstancias extraordinarias: el gobierno puede sustituir a las entidades locales (regiones, provincias, grandes ciudades y municipios) en el ejercicio de sus poderes por razones de seguridad pública, para preservar la unidad legal y económica o para garantizar un nivel asistencial esencial respecto de derechos civiles y sociales (artículo 120 de la Constitución). Además, el gobierno puede aprobar decretos-leyes, con fuerza de ley, ante situaciones extraordinarias de urgencia y necesidad (Artículo 77 de la Constitución), que deben presentarse el mismo día a las Cámaras las cuales, incluso en caso de estar disueltas, se convocan expresamente y se reúnen, dentro del plazo de 5 días, para debatir y votar la conveniencia de su conversión en leyes, lo que se prevé en un plazo máximo de 60 días desde su adopción, de modo que, si no se produce dicha aprobación por ambas Cámaras quedan sin vigor ab initio. 
derecho de la Unión Europea. Se adoptaron, sobre esta base, ocho decretos-leyes ${ }^{28}$, algunos de los cuales se han convertido en ley, otros se han derogado.

En este marco, se aprobaron órdenes del Ministro de Sanidad al amparo de la ley 833 de 23 de diciembre de 1978 de la institución del servicio sanitario nacional, cuyo artículo 32 ha prestado cobertura a las medidas de cuarentena de 14 días y confinamiento domiciliario, así como la suspensión de reuniones públicas, actividades educativas comerciales y culturales, y transporte público. Un primer decreto-ley número 6, de 23 de febrero de 2020, estableció por parte del gobierno un elenco de medidas que las autoridades nacionales competentes pudieran adoptar para contener la pandemia, incluyendo, entre otras, la prohibición de la salida o la entrada en un municipio afectado con alta incidencia, y la suspensión del transporte de bienes y personas así como la actividad educativa. La implementación de dichas medidas se realizó por decretos del primer ministro, incluyendo medidas restrictivas en una zona roja de 10 municipios a otros municipios de las regiones central y del norte y finalmente se extendió a la totalidad del territorio nacional. Se adoptaron sucesivas medidas administrativas, financieras y legales en decretos-leyes.

La crítica fundamental se ha vertido, como viene siendo habitual en otros países, en relación con el sistema de fuentes y la intervención en el ámbito de los derechos. Se ha dicho que la herramienta fundamental para la gestión de los estados de emergencia no es el decreto del Presidente del Consejo de ministros, que es una fuente del derecho no prevista expresamente en la Constitución y tampoco prevista por la ley número 400 de 1988 sobre la estructura del poder normativo del gobierno, y no está sujeto, a diferencia del decreto-ley, a la obligación de su conversión en ley. Sin embargo, los decretos del Presidente del Consejo de Ministros ha sido la vía más utilizada durante la emergencia de salud causada por la pandemia en Italia ${ }^{29}$. Piénsese que, además, la Constitución italiana establece una forma de gobierno parlamentaria con tendencia asamblearia, en la que el Jefe del gobierno no ejerce funciones asimilables a las del Canciller alemán, el Primer Ministro británico, o el Presidente del Gobierno español, sino que es un primus inter pares que ejerce un papel coordinador, mediador y promotor de actividades ministeriales, no un papel de dirección política o de diseño de las líneas políticas del Ejecutivo ${ }^{30}$. Adicionalmente, se generalizaron

28 6/2020, 9/2020, 11/2020, 14/2020, 18/2020, 19/2020, 22/2020 y 23/2020.

29 Mezzetti, L., «La pandemia de la Constitución: el impacto del Covid-19 en el sistema constitucional italiano», en González Martín, N. y Valadés, D. (coords.), Emergencia sanitaria por Covid-10. Derecho comparado, UNAM, México, 2020, p. 104. La marginación del parlamento en cuanto a la escasez de control en un discutible sistema de fuentes como el descrito ha sido puesta de manifiesto por FerRARo, L., «Italia y el COVID-19: el orden constitucional puesto a prueba en la emergencia», en ArNaldo Alcubilla, E., y Canosa Usera, R., El derecho constitucional ante el Covid-19, Wolters Kluwer, Madrid, 2020, p. 341.

30 Art. 95 de la Constitución: «El Presidente del Consejo de Ministros dirige la política general del Gobierno y es responsable de ella. Él mantiene la unidad de dirección política y administrativa, promoviendo y coordinando la actividad de los Ministros». Puede comprenderse, no obstante, la conveniencia de esta solución desde el lado más pragmático: que en un gobierno de coalición en que existen frecuentes fracturas, el 
los mensajes televisivos del Presidente para informar a los ciudadanos en lugar de comparecer en el parlamento. Desde el ámbito de los derechos limitados, se aprecia también en Italia la crítica de la insuficiencia del rango normativo. El derecho fundamental a la intimidad derivado del artículo 15 de la Constitución se ve modulado mediante la adopción del sistema de monitoreo del contagio a través de una aplicación telemática, la libertad de circulación y residencia reconocida en el artículo 16 se ha limitado por razones de salud y seguridad, no por ley, de acuerdo con lo que la Constitución misma exige, sino por decreto del Presidente del Consejo de Ministros. La libertad de reunión del artículo 17 se ha sometido a restricciones en lugares abiertos al público y el artículo 19 sobre libertad religiosa, mediante disposiciones administrativas del gobierno. Similares argumentos pueden darse en relación con la realización de pruebas de salud obligatorias, artículo 32, y la libertad de empresa y el derecho de propiedad artículos 41 y 42, que se limitaron por disposiciones administrativas al igual que la libertad de enseñanza (escuelas y universidades, arts. 33 y 34 ).

Asimismo, se ha evidenciado una centralización de los poderes reguladores mediante actos administrativos que ha permitido desplazar la división de competencias legislativas entre el Estado y las regiones contenida en el artículo 117.3 de la Constitución ${ }^{31}$. Se ha demostrado la existencia de realidades regionales con gran capacidad de gestión, superando a la del Estado, y, paralelamente, un nuevo papel de los presidentes de las regiones, coloquialmente definidos como gobernadores, que en Lombardía, Véneto y Emilia-Romania han diseñado incluso sus propias pautas políticas. En el otro extremo, el caso de la región de Campania, cuya gestión negativa de la crisis desembocó en una amenaza de cierre de fronteras por parte del presidente de dicha región, algo prohibido por el artículo 120 de la Constitución.

En cuanto a la jurisprudencia de la Corte Costituzionale, la Sentencia 37/2021, de 24 de febrero ${ }^{32}$ es especialmente importante para delimitar las competencias del Estado y de las Regiones en la gestión de la pandemia. Además, contiene el principal pronunciamiento hasta el momento sobre la constitucionalidad del uso de los Decretos del Presidente del Consejo de Ministros para establecer la mayor parte de las medidas excepcionales durante la pandemia. También, en un nivel principalmente competencial, aunque en este caso entre poderes del Estado la Corte se ha pronunciado en las Ordinanze 66 y 67/2021, por las que se produce la inadmisión de conflictos de atribución entre poderes del Estado, interpuesto por

recurso a la delegación de la gestión de la emergencia en el Presidente del Consejo constituyó un punto de mediación precario pero suficiente.

31 Que reserva a las regiones competencias legislativas en educación, protección de la salud, alimentación, protección civil, gobierno territorial, puertos civiles y aeropuertos, redes de transporte y navegación.

32 Sobre la Ley de la Región del Valle de Aosta de 9 de diciembre de 2020, n. 11 (Misure di contenimento della diffusione del virus SARS-COV-2 nelle attività sociali ed economiche della Regione autonoma Valle d'Aosta in relazione allo stato d'emergenza), previamente suspendida por la Ordinanza 4/2021, de 14 de enero. 
los Diputados Vittorio Sgarbi y Sara Cunial frente a los actos adoptados por el Gobierno para afrontar la emergencia de la pandemia desde el inicio de esta.

En relación con los poderes del Consejo de Ministros para fijar la fecha del referéndum de reforma constitucional la Corte dictó la Ordinanza 195/2020, que declara inadmisible el recurso por conflicto de atribución promovido por el Comité promotor de la consulta.

\section{PAÍSES DE LA ÓRBITA DEL COMMON LAW ${ }^{33}$}

Menor margen de crítica, en principio, queda en relación con las soluciones normativas desde un punto de vista general, dado que en estos ordenamientos la flexibilidad constitucional está, de suyo, incorporada, desde los conceptos de martial law y devolution of powers propios del constitucionalismo británico que se extienden a toda su órbita de influencia jurídica. También es interesante, como sucede en el caso de Estados Unidos, contemplar la cuestión desde la perspectiva de un sistema presidencialista y federal. No obstante, veremos cómo la crítica ha emergido también, aunque con matices diferentes.

En Estados Unidos la Constitución no contiene, salvo la suspensión del habeas corpus en tiempo de guerra, mención alguna sobre el derecho de excepción, lo que puede sugerir una aproximación a la lectura constitucional de las crisis desde una aproximación al modelo «business as usual» ${ }^{34}$. La Corte suprema, incluso, en ex parte Milligan (1866) ${ }^{35}$ sentó el principio de que «la misma ley se aplica en la paz y en la guerra», aunque posteriormente, en el contexto de la segunda guerra mundial, matizó esta doctrina en Korematsu v. United States $(1944)^{36}$ en que se apodera al Presidente y al Parlamento a gestionar (económicamente) la guerra, por lo que se dota al sistema de la flexibilidad necesaria. Hoy la aproximación tiende a ver poderes presidenciales de emergencia implícitos en las cláusulas constitucionales que confieren al Presidente competencias ejecutivas, en materia de asuntos exteriores y como comandante en jefe de las Fuerzas Armadas ${ }^{37}$. Sobre esta base, el Presidente Trump declaró el 13 de marzo de 2020 la emergencia de salud según la National Emergencies Act de $1976^{38}$, que supone la activación de los poderes especiales de que dispone el Presidente, en el ámbito de sus prerrogativas constitucionales (art. II de

33 Sobre el constitucionalismo del Common Law, el principio de soberanía parlamentaria y los poderes de emergencia, véase Greene, A., Permanent states of emergency and the rule of law, Hart Publishing, Oxford, 2018, pp. 176-189.

34 La justificación histórica de esta ausencia de mención constitucional y del rechazo al modelo de dictadura comisoria por los padres constituyentes, en GreEne, A., op. cit., p. 162

3571 US (4 Wall) 2, 120-121.

36323 US 214 .

37 Greene, A., op. cit., pp. 161-165.

38 DCPD-202000156 — Proclamation 9994-Declaring a National Emergency Concerning the Novel Coronavirus Disease (COVID-19) Outbreak, in www.govinfo.gov. 
la Constitución: executive orders ${ }^{39}$, proclamations $^{40}$, presidential memoranda $^{41}$ ) a través del complejo de departamentos y agencias del gobierno federal, sin perjuicio de respetar el papel del Congreso, el cual principalmente ha realizado una función presupuestaria para la cobertura de las medidas presidenciales, así como una función de control político sobre la actuación de la administración. A nivel de los Estados, puede hablarse de una colaboración similar entre el legislativo y el ejecutivo en el ejercicio de las amplias competencias de los Estados en relación con la imposición de límites a los derechos. El Estado federal ha realizado un papel general de coordinación y de dirección, sin perjuicio de las posibilidades que confiere la Stafford Act de 1988, en que se permite, mediante la declaración del estado de emergencia sanitaria grave (mayor disaster), cuando el ámbito de la misma es supraestatal, instarse la colaboración con el Estado federal aun respetando el principio de subsidiariedad, por cuanto no se ha permitido, pese a haberse producido dicha declaración en todos los Estados, que la Federación disponga de un poder de lock out generalizado. Asimismo, sin que el derecho a la asistencia sanitaria tenga un reconocimiento expreso en la Constitución, la legislación federal ha instituido programas de asistencia pública a favor de sujetos considerados vulnerables (Medicare y Madicaid). Por tanto, sin duda, las mayores restricciones de las libertades se han realizado por parte de los Estados, en coherencia con las amplias competencias residuales en materia de gestión de la emergencia y de los poderes de que constitucionalmente disponen, directamente vinculantes para los ciudadanos: imposición de confinamientos, cuarentenas, clausura más o menos amplia de instituciones educativas, actividades económicas y actuaciones públicas. Ello ha conducido a una aproximación a la solución diferenciada según sectores y Estados, controlada judicialmente en relación con los principios de necesidad, proporcionalidad y no discriminación ${ }^{42}$, cuando no al conflicto político con la Federación, que incluso ha podido alimentarse en razón de las diferentes estrategias y visiones políticas ${ }^{43}$. Las limitaciones de derechos en cuestión, justificadas sobre la base de la disciplina del estado de emergencia y la tutela

39 Ad ex. DCPD-202000172 — Executive Order 13909-Prioritizing and Allocating Health and Medical Resources to Respond to the Spread of COVID-19 (18 marzo 2020), in www.govinfo.gov, en aplicación de la Defense Production Act del 1950 (Pub.L. 81-774, 64 Stat. 798, 50 U.S.C. Chapter 55) requiriendo a las empresas privadas la ejecución de contratos de equipamiento médico necesario para el sistema de salud.

40 Ad ex. 85 FR 6709 - Suspension of Entry as Immigrants and Nonimmigrants of Persons Who Pose a Risk of Transmitting 2019 Novel Coronavirus and Other Appropriate Measures To Address This Risk, in www.govinfo.gov (31 junio 2020, seguida de otras análogas).

41 Memorandum on Providing Federal Support for Governors' Use of the National Guard to Respond to COVID-19, in www.federalregister.gov, (22 marzo 2020, seguido de otros análogos en relación con Estados concretos).

42 Por ejemplo, la posteriormente retirada ordenanza del Gobernador de Rodhe Island que vetaba el desplazamiento de vehículos procedentes exclusivamente del Estado de Nueva York, (T. GinsBurg, M. Versteeg, Can Emergency Powers Go Too Far? in www.tabletmag.com, 7 de abril 2020)

$43 \mathrm{La}$ diferencia de visión política entre Trump y los gobernadores de algunos estados, del partido demócrata, que inclinaba al primero a una rápida reapertura de la actividad para tutelar los intereses económicos y conjurar el riesgo de crisis, y a los segundos a la permanencia de las restricciones para conseguir una reducción de los contagios. 
de la salud pública, se han hecho realidad de modo diverso según los territorios interesados, y ello ha suscitado un contencioso tanto a nivel estatal como federal en relación con la necesidad y proporcionalidad exigidas respecto de las exigencias sanitarias ${ }^{44}$.

La Corte Suprema ${ }^{45}$ se ha pronunciado sobre las medidas impuestas en diversos ámbitos, especialmente en relación con la libertad y el ejercicio del culto y en el ámbito electoral, si bien en relación con muchas medidas y restricciones los pronunciamientos más importantes no han venido de la Corte Suprema de los Estados Unidos, sino de las Cortes Supremas estatales ${ }^{46}$.

En el Reino Unido la solución normativa ha venido de la mano del concepto de devolution contenido en la Public Health Act de 1967 (para Irlanda del Norte) y de 1984 (para Inglaterra, Escocia y Gales), modificada esta última por la Health and Social Care Act de 2008 (únicamente vigente para Inglaterra y Gales). Estas normas proporcionan cobertura jurídica para la adopción de las medidas extraordinarias necesarias (restricciones o condiciones sobre personas, cosas o lugares) a instancia del Ministro o departamento competente para la protección de la salud, con la debida proporcionalidad y adecuadas para prevenir, contener o controlar el contagio. En todo caso las medidas requieren el examen, previo, y si no es posible, posterior, del Parlamento o del órgano territorial homólogo ${ }^{47}$.

Sin perjuicio de lo previsto en las anteriores normas, se ha aprobado, en el plazo brevísimo de una semana ${ }^{48}$, la Coronavirus Act 2020, en vigor desde el 25 de

44 Spagnoli, F., «L'emergenza COVID-19 in Spagna e negli Stati Uniti: un bilancio comparato», en L'emergenza sanitaria da COVID-19: una prospettiva di diritto comparato, a cura di TARCHI, R., Rivista del Gruppo di Pisa. Dibattito aperto sul dirito e la Giustizia Costituzionale-Quaderno, n. ${ }^{\circ}$ 1, p. 47.

45 En relación con las restricciones impuestas al culto, rezo y estudio de textos sagrados las resoluciones han sido tomadas en respuesta a solicitudes de injunctive relief. En casi todos los casos, tomadas por mayorías 5-4 (con un giro en los criterios predominantes antes del fallecimiento de J. Ginsburg y después del nombramiento de J. Barrett). Todas han sido objeto de extensas opiniones o votos particulares. Destacan las opiniones Roman Catholic Diocese of Brooklin v. Cuomo, de 25 de noviembre de 2020 (caso 20A87) y Tandon v. Newsom, de 9 de abril de 2021 (caso 20A151). Esta última considera que las restricciones impuestas a las reuniones celebradas para el rezo y estudio de la Biblia por el Gobierno de California suponen una violación de la Primera Enmienda, ya que resultaban discriminadas respecto a otras reuniones e instalaciones seculares. En otros casos las resoluciones carecen de fundamentaciones jurídicas tan extensas, aunque los votos u opiniones particulares, tanto concurrentes como discrepantes, contienen razonamientos bastante más detallados. Entre otros South Bay United Pentecostal Church v. Newsom (20A136), Calvary Chapel Dayton Valley v. Sisolak (19A1070), Harvest Rock Church v. Newsom (20A137), Gateway City Church v. Newsom (20A138), Denver Bible Church v. Polis (20A163). En relación con la celebración de elecciones y la forma de voto también ha habido casos importantes. Por ejemplo (en los dos casos resolviendo una application for stay) como Republican National Committee v. Democratic National Committee, de abril de 2020 (19A1016), y Merrill v. Alabama (20A67), de octubre de 2020. Otros pronunciamientos se han referido a restricciones y medidas sanitarias en el ámbito penitenciario (Barnes v. Ahlman, en una application for a stay, resuelta el 5 de agosto de 2020).

46 Como emblemáticamente ha sucedido en el de Wisconsin (desde el confinamiento domiciliario, en Wisconsin Legislature v. Palm, de 13 de mayo de 2020, hasta la obligatoriedad del uso de mascarillas, en Fabrick v. Evers, de 31 de marzo de 2021).

47 Public Health (Control of Disease) Act 1984, s. 45R (2); Public Health Act (Northern Ireland) 1967 , s. 25Q (2).

48 La iniciativa entró en la Cámara el día 19. 
marzo, gracias, en buena, medida a la existencia de mayoría absoluta conservadora. Extremos significativos son la sunset clause (su vigencia temporal es notablemente larga-pasados dos años desde su entrada en vigor la norma queda automáticamente derogada-Sección 89) con una revisión parlamentaria semestral, no obstante, a partir de ese momento, sobre la oportunidad de su mantener o revocar el estado de emergencia ${ }^{49}$. Esto fue en su momento muy criticado, y contrasta con su homóloga Coronavirus Scotland Act 2020 que prevé una revisión parlamentaria semestral desde el inicio de su vigencia. La mencionada fecha de caducidad, no obstante, puede demorarse (sección 90) por razones justificadas e incluso parte de la legislación de emergencia puede permanecer en vigor incluso «mucho tiempo después» ${ }^{50}$ de la fecha propuesta de finalización de la vigencia de la norma.

La Coronavirus Act ha sido criticada por su cercanía conceptual a la denominada «cláusula Enrique VIII ${ }^{51}$ y ha supuesto una reducción del control (parlamentario y judicial $)^{52}$ sobre las medidas adoptadas por parte de la autoridad gubernativa, con potenciales implicaciones en los derechos (detención, cuarentena, libertad de reunión, garantías en el proceso penal). Entra, además, en el concepto de devolution of powers al incluir la coordinación de las competencias territoriales a través de la Comisión de emergencias civiles Civil Contingencies Committee (COBR).

El Reino Unido ha optado por aprobar esta ley, y no utilizar la Civil Contingencies Act de 2004, que podría haberse empleado, al menos desde el punto de vista de su supuesto de hecho, por cuanto que el contagio del coronavirus puede considerarse «amenaza de serio perjuicio para el bienestar humano», en términos de pérdida de vidas humanas, daño ambiental en términos de contaminación, paralización o crisis organizativa en los servicios de salud ${ }^{53}$. Dicha opción cabe enmarcarla en la imprevisibilidad de la duración temporal y de las mismas medidas, pero, sobre todo, a la conveniencia de diseñar un instrumento normativo con rango parlamentario que permitiera obviar las necesarias autorizaciones parlamentarias (secciones 27 y 28) para la prórroga de las medidas exigida por la Civil Contingencies Act.

Las medidas restrictivas de la libertad de circulación y desplazamiento por confinamiento domiciliario con las excepciones usuales en el resto de los países se

49 HoAr, F., «A disproportionate interference: The Coronavirus Regulations and the ECHR», UK Human Rights Blog, 21 de abril de 2020.

50 Molloy, S., «Covid-19, Emergency Legislation and Sunset Clauses», U.K. Const. L. Blog, 8 de abril de 2020 .

51 La Proclamation of the Crown Act (1539) permitió al Rey Enrique VIII legislar por Decretos, que, incluso pudiendo afectar a la vida y a la propiedad, vinculaban como si se tratara de leyes del parlamento, fue considerada por BLACKSTONE como introductoria de la tiranía más despótica (Online Library of Liberty: Commentaries on the Laws of England in Four Books, vol. 1, Chapter 7, p. 164. Esta cláusula, tal como se entiende hoy en día, permite al poder ejecutivo por razones de excepcionalidad, modificar o incluso suspender leyes del parlamento mediante normativa de rango secundario (Regulations) si bien se necesita confirmación parlamentaria posterior.

52 Cfr. Tierney, S. y King, J., «The Coronavirus Bill», U.K. Const. L. Blog, 24 de marzo de 2020.

53 Section 1 Civil Contingencies Act 2004: «event or situation which threatens serious damage to human welfare» «to the environment» «loss of human life», «human illness or injury», «disruption of services relating to health», «contamination of land, water or air with biological, chemical or radio-active matter». 
implementaron vía Regulations emanadas del Secretario de Estado bajo la Public Health Act 1984. Esto ha sido criticado por cuanto que el control parlamentario queda muy limitado por la vigencia temporal antedicha y sólo queda el control judicial de dicha normativa gubernativa; y por otra parte, hubiera podido utilizarse la cobertura jurídica de la Coronavirus Act que permite que tales medidas se tomasen por los Ministros competentes, y, por tanto, aunque se tratase de normativa gubernamental también, estuviera en el rango de «legislación secundaria», más que meramente reglamentario, diríamos, con las categorías del sistema de fuentes español ${ }^{54}$. Finalmente, si bien la norma se aplica únicamente cuando existan periodos de control del contagio expresamente declarados por las autoridades, de hecho, es posible una «nueva normalidad» restrictiva de derechos fuera de dichos periodos; además, la ley extiende la posibilidad de limitar derechos de libertad a personas que no necesariamente cuentan con el asesoramiento de expertos ${ }^{55}$, que es lo que demanda el TEDH (Enhorn v. Sweden -European Court of Human Rights, Application no. 56529/00, 25 de enero 2005) ${ }^{56}$.

\section{LA PRAXIS DEL ESTADO DE ALARMA COMO MUTACIÓN CONSTITUCIONAL HASTA LA STC DE 14 DE JULIO DE 2021}

Existe, como es sabido, un modo informal de modificación del significado de la Constitución, que se ha denominado mutación constitucional. El concepto es originario de la doctrina alemana del Derecho Público ${ }^{57}$. La mutación deja inalterado el texto, pero implica un cambio en el significado del mismo. Es útil —a veces, no tan sencillo- distinguir la mutación de la quiebra de la Constitución ${ }^{58}$ :

54 Grogan, J., «Right Restriction or Restricting Rights? The UK Acts to Address COVID-19», Verfassungsblog, 17 de abril de 2020.

55 Pugh, J., "The United Kingdom's Coronavirus Act, Deprivations of Liberty, and The Right to Liberty and Security of the Person», Journal of Law and the Biosciences, vol. 7, n. ${ }^{\circ}$ 1, 2020.

56 Para terminar con esta necesariamente breve panorámica comparada, en la que nos hemos centrado en los Estados de nuestro entorno de la Unión Europea y en los más emblemáticos del sistema del Common Law, Estados Unidos y Gran Bretaña, puede consultarse una panorámica del estado de la cuestión en los países de América Latina, en Cervantes, A., Matarrita, M. y Reca, S., «Los estados de excepción en tiempos de pandemia: un estudio comparado en América Latina», Cuadernos Manuel Giménez Abad, n. ${ }^{20}$, 2020, pp. 179206. Véase también Arnaldo Alcubilla, E., y Canosa Usera, R., El derecho constitucional ante el Covid-19, Wolters Kluwer, Madrid, 2020.

57 Laband, P., Die Wandlungen der Deutschen Reichverfassung, Zahn \& Jaensch, 1896; y JellineK, G., Verfassungsänderung und Verfassungswandlung, O. Häring, 1906. Posteriormente escribió Hsü DAU LIN bajo la dirección de SMEnd, R., Die Verfassungswandlung, (trad. al castellano, Mutación de la Constitución, IVAP, Oñati, 1998), que distinguió cuatro tipos de mutación constitucional: las prácticas políticas no contempladas en la constitución, y que no entrañan una contradicción con la literalidad del texto, los supuestos de falta de ejercicio de preceptos constitucionales, las actuaciones políticas contrarias a la constitución y la interpretación constitucional.

58 De Vega, P., La reforma constitucional y la problemática del poder constituyente, Tecnos, Madrid, 1985, p. 194.

UNED. Teoría y Realidad Constitucional, núm. 48, 2021, ISSN 1139-5583, pp. 463-493 
la primera se refiere a cambios constitucionales que sin alterar el texto no suponen infracción de la Constitución, pues dicha infracción nos situaría ya ante una quiebra constitucional. Incluso dentro de la interpretación de la Constitución sería posible distinguir, todavía, la interpretación que supone una mutación y la interpretación que, por ser en sí misma anticonstitucional, de hecho, supone una quiebra de la Constitución. También hay que considerar que las mutaciones que suponen actuaciones contrarias a la Constitución son en realidad suspensiones de la vigencia de la misma ${ }^{59}$. Mi opinión es que, hasta la Sentencia del Tribunal Constitucional de 14 de julio de 2021, la praxis del estado de alarma en España ha venido constituyendo una mutación constitucional.

En 2010 se declaró un estado de alarma, cuando debía haberse declarado un estado de excepción, y se adoptaron medidas de estado de sitio $^{60}$.

En 2020 se «suspendieron derechos sin decirlo», como afirma la STC de 14 de julio de 2021, en su FJ 11 y señalamos en su momento ${ }^{61}$.

La suspensión de derechos se da cuando no es posible aplicar una mínima proporcionalidad en el conflicto entre un derecho y otro bien constitucionalmente protegido, sino que el derecho cede en todo caso. Se trata de una suspensión de la vigencia de la norma constitucional. Efectivamente, es una limitación o restricción de derechos el dejar en manos de un juez la aplicación del principio de proporcionalidad, como se ha hecho en los casos en que las Comunidades Autónomas, al amparo de las cláusulas generales contenidas en la legislación sanitaria ordinaria de urgencia ${ }^{62}$, han intervenido para establecer normativa general con incidencia en los derechos fundamentales, en que la última palabra sobre la juridicidad de dichas medidas la tienen hoy los Tribunales Superiores de Justicia (art. 10 LJCA) y, en

59 SÁNCHEZ GONZÁLEZ, S., «Reforma, mutación y quiebra constitucionales», TRC, n. ${ }^{\circ}$ 19, 2007, p. 301.

60 Sieira Mucientes, S., «Los estados excepcionales», Revista de las Cortes Generales, n. ${ }^{\circ} 104,2018$, p. 389. La norma (un simple real decreto) que declaró el estado de alarma supuso una militarización no simplemente operativa, sino la consideración de los controladores como personal militar, sometidos a las órdenes directas de los mandos militares en el control del tráfico aéreo, y, caso de incumplimiento, la sanción con arreglo a las leyes disciplinarias y penales militares. Esto supuso, de iure: a) Una suspensión del derecho de huelga - caso de que se hubiese querido instrumentar el conflicto por esta vía, de conformidad con su normativa reguladora (suspensión sólo permitida bajo el estado de excepción) puesto que su ejercicio hubiera resultado delictivo bajo la vigencia del estado de alarma, al poseer esta consideración en el Código Penal militar. Prohibición - y no simplemente limitación-, por tanto, de ejercicio del derecho fundamental del artículo 28 CE. b) Una extensión de la jurisdicción militar fuera del ámbito estrictamente castrense y de los supuestos de estado de sitio, que es el único ámbito constitucionalmente posible de este orden jurisdiccional (art. 117.5 CE) y la sumisión de los controladores aéreos a las leyes penales y disciplinarias militares, en atención a su consideración como personal militar.

61 Sieira Mucientes, S., «Estado de alarma», Eunomía. Revista en Cultura de la Legalidad, n. ${ }^{\circ}$ 19, 2020 , pp. 275-305.

62 Sobre el fundamento jurídico de las medidas adoptadas por las Comunidades Autónomas, existen tres leyes estatales (Ley 14/1986, de 25 de abril, General de Sanidad _LGS_, Ley Orgánica 3/1986, de 14 de abril, de Medidas Especiales en Materia de Salud Pública _LOMESP_, Ley 33/2011, de 4 de octubre, General de Salud Pública _ LGSP_, que habilitan a las autoridades sanitarias —en este caso, las Consejerías de Sanidad - a dictar una serie de medidas tipificadas para el caso de pandemia, así como otras de carácter innominado y subsidiario en las cláusulas generales contenidas en los artículos 26, 1 y 54 respectivamente. 
vía de recurso, el Tribunal Supremo. Pero recordemos que las normas declarativas de los estados excepcionales tienen fuerza de ley y por tanto sólo son recurribles ante el Tribunal Constitucional, estando sustraídas, por tanto, a toda posibilidad de ponderación y a la aplicación del principio de proporcionalidad en la jurisdicción ordinaria, quedando únicamente sometidas al control de constitucionalidad que aplica el principio de proporcionalidad con una intensidad mucho más matizada en su control al legislador (STC 136/1999) ${ }^{63}$. En ese sentido entendemos que ha existido suspensión de derechos fundamentales, en particular, el derecho a la libertad del art. $17^{64}$ y la libertad de residencia y desplazamiento del art. $19^{65}$, con el confinamiento domiciliario y las cuarentenas.

Como ha sido establecido recientemente en la STC de 14 de julio de 2021, FJ 11, y así lo vengo sosteniendo en trabajos precedentes, para la plena garantía los derechos fundamentales, por las importantes restricciones impuestas colectivamente a los ciudadanos, hubiera sido necesario declarar el estado de excepción, porque en el momento de declararse el estado de alarma, 14 de marzo de 2020, se cumplía el supuesto de hecho del estado de excepción, sin forzar en modo alguno la dicción literal del artículo 13.1 de la $\operatorname{LOEAES}^{66}$, el cual, a diferencia del estado de alarma, permite una lectura gradual relativa, en particular, al libre ejercicio de los derechos y libertades de los ciudadanos, que pudieran resultar tan gravemente alterados que el ejercicio de las potestades ordinarias fuera insuficiente para restablecerlo y mantenerlo. Efectivamente, en el momento de declarar el estado excepcional, a tenor de lo que estaba aconteciendo en Italia, que iba un paso por delante de España, resultaba claro que habrían de imponerse, como mínimo, medidas de confinamiento de la población — restricción del derecho a la libertad personal y de

63 Para un estudio más amplio del binomio limitación-suspensión, GómEz Fernández, I., «Limitación o suspensión? Una teoría de los límites de los derechos fundamentales para evaluar la adopción de los estados excepcionales», en GARRIDO LóPEZ, C. (coord.), Excepcionalidad y derecho: el estado de alarma en España, Fundación Giménez Abad, Zaragoza, 2021, pp. 95-105.

64 Como he sostenido (Sieira Mucientes, S., «Estado de alarma»..., op. cit., p. 296-7) la medida del confinamiento es la más extensa restricción de la libertad personal que, en general, la gran mayoría de ciudadanos no privados de libertad en virtud de actuaciones judiciales han sufrido en sus vidas, puesto que se ha obligado a permanecer en el domicilio bajo amenaza de sanciones penales y administrativas. Existe una monografía interesante al respecto, RAmón RiBAs, E., Desobediencia, estado de alarma y Covid-19, Tirant lo Blanch, Valencia, 2021. En contra, Tehres v. Rumania, STEDH de 20 de mayo de 2021, con unos presupuestos distintos al haberse declarado allí la suspensión de la vigencia de los derechos por estado de excepción, siendo comunicada como tal por dicho Estado en tiempo y forma.

65 Por todos, Cotino Hueso, L., «La (in)constitucionalidad de las restricciones y suspensión de la libertad de circulación por el confinamiento frente a la COVID», en GARrido López, C., Excepcionalidad y derecho: el estado de alarma en España, Fundación Manuel Giménez Abad, Zaragoza, 2021, pp. 177 y ss.

66 «Cuando el libre ejercicio de los derechos y libertades de los ciudadanos, el normal funcionamiento de las instituciones democráticas, el de los servicios públicos esenciales para la comunidad, o cualquier otro aspecto del orden público, resulten tan gravemente alterados que el ejercicio de las potestades ordinarias fuera insuficiente para restablecerlo y mantenerlo, el Gobierno, de acuerdo con el apartado tres del artículo ciento dieciséis de la Constitución, podrá solicitar del Congreso de los Diputados autorización para declarar el estado de excepción». Así se desprende también del FJ 11 de la STC de 14 de julio de 2021. 
la libertad de circulación y desplazamiento (arts. 17 y 19 de la CE). Como en su momento escribí ${ }^{67}$, sin cuestionar materialmente las medidas tomadas, que en todo caso parecieron necesarias y proporcionadas a la autoridad competente según el criterio del Centro de Coordinación y de Alertas y Emergencias Sanitarias, la crítica brotaba en relación con la eventual suspensión general de derechos fundamentales que comportaron dichas medidas, en particular la del confinamiento domiciliario, que hubiera estado justificada por medio de un estado de excepción. Apunté en su momento, además, que no es particularmente difícil declarar un estado de excepción en España pues exige una autorización en el Congreso por mayoría simple (art. 13 de la LOEAES), mayoría que estaba en aquellas fechas asegurada (el Pleno de la semana que aprobó la primera prórroga del estado de alarma, primera ocasión en que se votaba en la Cámara Baja tras la comunicación del Gobierno sobre su declaración, fueron convalidados por una amplia mayoría varios Decretos-Leyes, como sucedió con la misma prórroga de dicho estado (Diario de Sesiones del Congreso de los Diputados, Pleno, 25 de marzo de 2020). Nada hubiera obstado que la misma semana en que se declaró el estado de alarma, en lugar de una mera comunicación del real decreto declarativo del estado de alarma del día 14 de marzo, el Gobierno hubiera solicitado al Congreso una autorización del estado de excepción y su votación, que hubiera resultado, a todas luces, previsiblemente, favorable.

El tercer estado de alarma en España fue declarado por real decreto 900/2020, de 9 de octubre ${ }^{68}$, afectando exclusivamente a la capital, Madrid, y a otros grandes municipios de la Comunidad Autónoma, durante 15 días. Este real decreto reprodujo, en esencia, las limitaciones de la libertad de circulación aprobadas una semana antes por el Gobierno regional en ejecución de una Orden del Ministro de Sanidad, cuya ratificación judicial denegaron los tribunales por falta de cobertura legal $^{69}$. La medida que afectaba a la limitación de movilidad fue objeto de ratificación mediante Auto 116/2020, de 24 de septiembre, del Tribunal Superior de

67 Sieira Mucientes, S., «Estado de alarma», op. cit., p. 296. Una síntesis de las posiciones doctrinales en las pp. 292-297.

68 BOE extraordinario del propio día 9, con el fin de establecer las medidas necesarias para responder ante situaciones de especial riesgo por transmisión no controlada de infecciones causadas por el SARS-CoV-2, al amparo de la Ley Orgánica 4/1981, de 1 de junio, de los Estados de Alarma, Excepción y Sitio.

69 En el modelo llamado de «cogobernanza» establecido en el Real Decreto-Ley 21/2020, de 9 de junio, la Comunidad de Madrid comenzó a adoptar medidas para luchar contra el virus, a punto de finalizar (el 21 de junio) la última prórroga (dispuesta por Real Decreto 555/2020, de 5 de junio) del estado de alarma declarado en marzo. Las medidas más intensamente restrictivas se dictaron mediante la Orden 1178/2020, de 18 de septiembre (BOCM del 19), de la Consejería de Sanidad, aplicables en núcleos de población correspondientes a determinadas zonas básicas de salud, como consecuencia de la evolución epidemiológica. La medida más importante fue la restricción de la entrada y salida de personas de los ámbitos territoriales de las áreas de salud señaladas salvo para desplazamientos justificados, si bien se permitió la circulación de personas residentes dentro de los ámbitos territoriales afectados, respetando las medidas de protección, desaconsejándose, no obstante, los desplazamientos y actividades no imprescindibles (art. 2), junto con mayores restricciones en la actividad deportiva, las reuniones públicas o privadas, la hostelería y la restauración — con hora de cierre a las $22 \mathrm{~h}$. 
Justicia de Madrid ${ }^{70}$, que concluyó que la misma resultaba necesaria, proporcional e idónea para el fin perseguido, evitar la mayor difusión a otras zonas de una enfermedad altamente contagiosa, teniendo en cuenta el precedente sentado por la Sentencia 594/2020, de 28 de agosto, que sostuvo, ponderando las circunstancias, la suficiencia de cobertura legal y la competencia de las autoridades sanitarias autonómicas. Posteriormente, el enfrentamiento entre el Ministerio de Sanidad y la Comunidad de Madrid se visibilizó en la reunión del Consejo Interterritorial del Sistema Nacional de Salud del 30 de septiembre de 2020, en la que, con el voto en contra de cuatro Comunidades Autónomas, Andalucía, Catalunya, Galicia y Madrid, se adoptó la denominada «Declaración de Actuaciones Coordinadas en Salud Pública» plasmada en una Resolución del Consejo Interterritorial del Sistema Nacional de Salud, notificada a las Comunidades Autónomas mediante Orden comunicada del Ministerio de Sanidad del mismo día 30 de septiembre. Una vez notificada la Orden comunicada la Comunidad de Madrid interpuso un recurso contra el Acuerdo anterior y las medidas impuestas, con petición de medidas cautelares (que luego retiraría), procediendo, no obstante, al cumplimiento de la misma mediante la Orden 1273/2020, de 1 de octubre, de la Consejería de $S_{\text {Sanidad }}{ }^{71}$. Interesada la ratificación de dicha orden, sobre el presupuesto establecido en la citada Sentencia 594/2020, de 28 de agosto, el Auto 128/2020 de 8 de octubre de la Sección 8. ${ }^{a}$ de la Sala de lo Contencioso-Administrativo del TSJ de Madrid analiza a la luz de la doctrina del Tribunal Constitucional, «cuáles de dichas medidas limitan o restringen derechos fundamentales de los ciudadanos y si tal limitación encuentra, primero, cobertura legal, siendo o no competente la Administración que las acuerda, y además sí respeta los parámetros de justificación, idoneidad y proporcionalidad que la doctrina constitucional viene exigiendo en la restricción, o limitación de dichos derechos esenciales». Pues bien, prefigurando en buena medida la conclusión de la reciente STC de 14 de julio, concluye el TSJ de Madrid que no aprecia «en la regulación que contiene el artículo 65 de la Ley 16/2003, de 28 de mayo, de Cohesión y Calidad del Sistema Nacional de Salud, habilitación legal alguna para el establecimiento de medidas limitativas del derecho fundamental a la libertad de desplazamiento y circulación de las personas por el territorio nacional (artículo $19 \mathrm{CE}$ ), o de cualquier otro derecho fundamental» ${ }^{72}$. Y, por tanto, «[l]a consecuencia de tal apreciación es que las medidas limi-

70 En aplicación del nuevo artículo 10 de la Ley de la Jurisdicción Contencioso-Administrativa modificada por disposición final 2.2 de la Ley 3/2020, de 18 de septiembre.

71 Esta Orden, adicionalmente, soluciona problemas de aplicación espacio-temporales al no ser coincidentes los municipios contemplados en la Orden comunicada con los que habían sido objeto de medidas anteriormente adoptadas por la Comunidad de Madrid.

72 «Ninguna mención se hace en el precepto, ya sea de forma directa o indirecta, a la posible limitación de derechos fundamentales con motivo del ejercicio de las funciones legalmente encomendadas al Consejo Interterritorial del Sistema Nacional de Salud»; y, enfatiza, «menos aún se establecen en forma alguna los presupuestos materiales de una eventual limitación de derechos fundamentales, inherentes a las más elementales exigencias de certeza y seguridad jurídica». Tampoco, a su juicio, puede encontrarse dicha cobertura legal en la reforma de 
tativas de derechos fundamentales que establece la Orden 1273/2020, de 1 de octubre, de la Consejería de Sanidad, meramente en ejecución de la Orden comunicada de 30 de septiembre de 2020, constituyen una injerencia de los poderes públicos en los derechos fundamentales de los ciudadanos sin habilitación legal que la ampare, es decir, no autorizada por sus representantes en las Cortes Generales, por lo que no puede ser ratificada».

Al denegar el Auto del Tribunal Superior de Justicia de Madrid la suficiencia de la cobertura jurídica de las medidas, el Gobierno de la Nación declaró de nuevo el estado de alarma, mediante el Real Decreto 900/2020, de 9 de octubre, para imponer las mismas medidas restrictivas de derechos y libertades (que no había ratificado el Tribunal Superior de Justicia), exclusivamente en la Comunidad de Madrid. Por similares razones a las que se aducen en el fallo del TC de 14 de julio, el decreto declarativo del tercer estado de alarma en España, podría estimarse que es asimismo inconstitucional ${ }^{73}$.

El cuarto y último estado de alarma fue declarado por Real Decreto 926/2020, de 25 de octubre, vigente hasta el 9 de noviembre, y su prórroga instrumentada por Real Decreto 956/2020, de 3 de noviembre tuvo una duración extraordinaria de 6 meses, hasta el 9 de mayo de 2021. Cierto es que la prórroga del primer estado de alarma en 2010 ya tuvo una duración extraordinaria (20 días) pero lejos de lo que en el último estado de alarma se ha aprobado: una vigencia semestral desborda con mucho la dicción literal de la Constitución, que prevé que «el estado de alarma tendrá una duración de 15 días, prorrogables» (art. 6 LOEAES). Aunque la duración de la prórroga no se establece en la Ley Orgánica, a diferencia de la duración de la prórroga del estado de excepción — que, siendo un estado cuya declaración comporta una mayor gravedad, queda limitada a 30 días - art. 15 LOEAES), podría pensarse que carece de todo sentido de la proporción que un estado que dura quince días pueda ser prorrogado durante seis meses ${ }^{74}$. Cierto es

la Ley 16/2003, de 28 de mayo, de Cohesión y Calidad del Sistema Nacional de Salud, realizada por el Real Decreto-Ley 21/2020, de 9 de junio, si bien el Tribunal señala «[r]esulta llamativo que ante el escenario sanitario descrito no se abordara una reforma de nuestro marco normativo más acorde con las confesadas necesidades de combatir eficazmente la pandemia del Covid-19 y afrontar la grave crisis sanitaria que padece el país, pese al consenso doctrinal existente acerca de que la regulación actual de los instrumentos normativos que permiten la limitación de derechos fundamentales, con el objeto de proteger la integridad física (artículo 15 CE) y la salud (artículo $43 \mathrm{CE}$ ), íntimamente conectados entre sí, resulta ciertamente deficiente y necesitada de clarificación».

73 En idéntico sentido, existió un pronunciamiento judicial en aplicación del artículo 8.6.2 de la LJCA, en su redacción de 2015, modificada por la ley 2020, la sentencia de la juez de guardia de Lleida de 12 de julio de 2020 que suspendió cautelarmente las medidas especiales en materia de salud pública que establecían un confinamiento poblacional general para la comarca del Segriá, acordadas por la Generalitat de Catalunya, considerando que dichas medidas excedían de lo que en aplicación de la LOMESP correspondía al Govern de Catalunya. En respuesta a esta sentencia se dictó un decreto-ley cuyo eventual control corresponderá asimismo al Tribunal Constitucional.

74 Aragón Reyes, M., «Epílogo», en Biglino Campos, P. y Durán Alba, J. F., (Dirs), Los efectos horizontales de la COVD-19 sobre el sistema constitucional: estudios sobre la primera oleada, Fundación Manuel Giménez Abad, Zaragoza, 2021, p. 569, señala que el pronunciamiento periódico de la Cámara sobre el mantenimiento de las condiciones excepcionales que justifican el Estado, para lo que las prórrogas deberían tener 
que las prórrogas del estado de alarma declarado en marzo, aun concediéndose todas, cada vez se aprobaban con mayorías más ajustadas, lo que en una lectura política suponía un desgaste para el gobierno. Pero ello no justifica eliminar jurídicamente, mediante un real decreto, la debida autorización parlamentaria para dar continuidad o levantar, a intervalos regulares de tiempo, tal como se ha previsto en la Ley Orgánica, a las medidas adoptadas, y ello, sin perjuicio de que se establezcan, como así se hizo, obligaciones de información bimensual por parte del Presidente del Gobierno y mensual por parte del Ministro de Sanidad, y con la posibilidad de que el Consejo Interterritorial del Sistema Nacional de Salud propusiera al gobierno, superado el plazo de 4 meses de vigencia, el levantamiento del estado de alarma. Esta última cuestión emparenta con el peligro de la tecnocracia, denunciado como hemos tenido ocasión de ver, por la Comisión de Venecia, que ha detectado un desplazamiento del centro de decisión político del parlamento a otro tipo de entidades extraparlamentarias. La Comisión de Venecia ha sido clara, además, en la necesidad del control parlamentario de las prórrogas ${ }^{75}$ e insiste, incluso, en que es el Parlamento el que debe disponer de la capacidad de apreciación del momento en que el estado excepcional debe ser levantado ${ }^{76}$.

idéntico plazo que la declaración, no puede quedar a la libre disposición de la mayoría de la cámara porque entonces se multaría a la minoría su derecho al ejercicio del control parlamentario. En contra, GARCía RocA entiende que el silencio que guarda la ley respecto de la duración de la prórroga en el estado de alarma es expresivo en comparación con la limitación de la duración de la prórroga en el estado de excepción, siendo así que las prohibiciones deben ser expresas y no inferidas de juicios lógicos. Al no haber plazo legal, si la prórroga pasa a ser una disposición del parlamento, la mayoría tiene discrecionalidad y el resultado, plena legitimidad democrática.

García RoCA, F. J., «El control parlamentario y otros contrapesos del gobierno en el estado de alarma: la experiencia del coronavirus» en BArceló Roja, D., DíAz Ricci, S., García Roca, J., y Guimaráes TeIXeIRA, M. E., (coords), COVID-19 y parlamentarismo. Los parlamentos en cuarentena, Universidad Nacional Autónoma de México e Instituto de Derecho Parlamentario, México, 2020, p. 25. Esta cuestión se encuentra pendiente de resolución por parte del TC el próximo 14 de septiembre, que permitirá además conocer la posición respecto de los Autos del Tribunal Supremo 2478/2020 y 2508/2020, junto con la delegación de autoridad en otras autoridades distintas del gobierno operada por el decreto de 25 de octubre de 2020.

75 En opinión de la Comisión de Venecia, la prolongación del estado de emergencia no siempre es la mejor solución para restablecer la seguridad pública y restaurar el estado de derecho. La experiencia de algunos otros países muestra que cuanto más dure el régimen de emergencia, más se alejará el Estado de los criterios objetivos que pueden haber validado el uso de los poderes de emergencia en primer lugar. Cuanto más tiempo persista la situación, menor será la justificación para tratar una situación como de carácter excepcional, con la consecuencia de que no puede abordarse mediante la aplicación de los instrumentos jurídicos normales. En virtud del PIDCP, el Comité de Derechos Humanos ha hecho hincapié en que las suspensiones deben ser temporales y ha criticado las emergencias prolongadas (véanse, por ejemplo, las observaciones finales del Comité sobre Israel (1998) y sobre Egipto (2002)). CDL-AD(2016)037, Turquía - Opinión sobre el Decreto de Urgencia Leyes No 667-676 adoptado tras el fallido golpe de Estado del 15 de julio de 2016, aprobado por la Comisión de Venecia en su 109a Sesión Plenaria, 9-10 de diciembre de 2016, párr. 41.

76 «El control legislativo de los actos y acciones de las autoridades del estado de emergencia y los procedimientos especiales para dicho control son importantes para la realización del Estado de derecho y la democracia. En la mayoría de las constituciones democráticas el ejecutivo tiene el derecho de declarar el estado de emergencia, sujeto a la aprobación parlamentaria. La cuestión de quién, cómo y cuándo se debe poner fin a un estado de emergencia no puede dejarse también en manos del ejecutivo, que goza de un mayor poder. Debe 
Así pues, en la praxis el estado de alarma en España ha merecido las mimas críticas que en derecho comparado, que suponen una elusión de las previsiones constitucionales: concentración del poder en el ejecutivo, fortalecido a expensas de un correlativo debilitamiento del parlamento, insuficiencia de cobertura constitucional y legal de las intensas medidas restrictivas de los derechos fundamentales, singularmente en relación con el de la libertad deambulatoria ${ }^{77}$, y establecimiento de un plazo de vigencia muy extenso que restringe o suprime, en la práctica, las autorizaciones parlamentarias prescritas normativamente para el mantenimiento de las medidas excepcionales. Todo ello ha supuesto una alteración de las reglas de juego del derecho de excepción por la vía de la inconfesada transformación (mutación) del ordenamiento constitucional.

\section{LA CONVENIENTE REFORMA CONSTITUCIONAL. REFORMAS CONSTITUCIONALES CON MOTIVO DE LA PANDEMIA}

De lo anteriormente expuesto se deriva la conveniencia de una reforma constitucional, para flexibilizar el derecho de excepción, que es, parece, lo que reclamaba, hasta ahora, su controvertida praxis, en vista a la más que probable aplicación del mismo por situaciones similares que puedan ocurrir en el futuro, y ello puede predicarse tanto dentro como fuera de nuestras fronteras. Ahora bien, es de sobra conocido que el art. 168 de la CE, que establece el procedimiento agravado de reforma constitucional, no se ha utilizado nunca, incluso se ha asegurado que sus requisitos son tan gravosos que podría aventurarse que no será utilizado jamás. Se ha puesto como ejemplo, paradójicamente, de mutación constitucional por inaplicación ${ }^{78}$. En España, además, resulta particularmente infrecuente el recurso al

ser la función del Parlamento. Esto implica una continuidad de la vida parlamentaria durante el período de emergencia. Por ello, algunas constituciones establecen explícitamente que el poder legislativo no puede ser disuelto durante el ejercicio de los poderes de emergencia. Estudio CDL-STD(1995)012, Poderes de emergencia, citado en la Compilación de la Comisión de Venecia, opiniones e informes sobre los estados de emergencia, Estudio 987/2020 de 16 de abril, CDL-PI(2020)003.

77 Para Díez-Picazo, L., la libertad protegida en el artículo 17 es «la libertad deambulatoria en cuanto a tal, no a los lugares donde uno puede moverse», Sistema de derechos fundamentales, Thomson, Civitas, Madrid, p. 232.

78 SÁnCHEZ GonZÁlez, S., «Reforma, mutación y quiebra ...», op. cit., p. 300. Y eso que, recuérdese, el 4 de marzo de 2005, fecha el Consejo de Ministros acordó solicitar al Consejo de Estado un informe sobre una serie de posibles modificaciones de la Constitución, destacando cuatro puntos: la supresión de la preferencia del varón en la sucesión al trono, la recepción en la Constitución del proceso de construcción europea, la inclusión de la denominación de las Comunidades Autónomas y la reforma del Senado. Hoy en día emergerían, sin duda, algunas cuestiones adicionales susceptibles de consulta, entre las que se encontraría, invariablemente, la conveniencia de la reforma de los artículos 116 y 55.2 en lo relativo a los estados excepcionales. El informe, aprobado el 16 de febrero de 2006, recomendaba, entre otras cuestiones, eliminar el anacrónico efecto de la Ley Sálica en la sucesión a la Corona, reforma que, de todas las indicadas, gozaría de un mayor consenso político, pudiendo superar la mayoría cualificada de $2 / 3$ en cada una de las Cámaras que exige el procedimiento, por suponer la más plena realización del valor superior de la igualdad. No obstante, la 
procedimiento de reforma constitucional ${ }^{79}$ mientras que en otros Estados esta cuestión se contempla con mayor naturalidad. De hecho, mirando fuera de nuestras fronteras, se han producido no pocas modificaciones constitucionales en los últimos tiempos ${ }^{80}$.

Pese a las dificultades que entraña la reforma constitucional, en España no han existido relevantes propuestas de reforma de la legislación orgánica en esta materia $^{81}$, pero la STC de 14 de julio, sobre la base de lo anteriormente sostenido por

oportunidad del planteamiento de una reforma constitucional en una cuestión delicada como lo es la Jefatura del Estado en relación con, precisamente, la igualdad como valor superior, aleja, aún más, la posibilidad, ya remota, de que se considere conveniente pasar por un proceso de reforma constitucional agravada, aprovechando el final de la legislatura, que es cuando resultaría menos gravoso para el gobierno cesante.

79 Si bien hay que decir que el Gobierno ha presentado recientemente, el 12 de mayo de 2021, un proyecto para aprobar la tercera reforma constitucional, por la vía ordinaria, tras las producidas en 1992 y 2011 , derivada de la necesaria coherencia con la Convención para la protección de las personas con discapacidad, que supondría la modificación del artículo 49 de la Carta Magna. (num. expte. 102/000001, Proyecto de reforma del artículo 49 de la Constitución Española, BOCG. Congreso de los Diputados n. ${ }^{\circ}$ A-54-1 de 21/05/2021, p. 1).

80 En Alemania, la última reforma se aprobó por la Gesetz zur Änderung des Grundgesetzes (artículos 104a y 143h), de 29 de septiembre de 2020, que modificó el artículo 104a de la Ley Fundamental, en el sentido de incrementar la responsabilidad de la Federación en la financiación de las prestaciones de alojamiento y calefacción en el ámbito del apoyo o seguridad básica de los desempleados. Además, introdujo un nuevo artículo, el $143 \mathrm{~h}$, dedicado a la compensación por las pérdidas en los ingresos sufridas por los municipios a consecuencia de la pandemia. Este último artículo estaba completamente ligado a la coyuntura y su entrada en vigor estaba complementada por una fecha para su fin, fijado el día 31 de diciembre de 2020. En Bélgica, de modo similar al caso español, la última modificación se realizó por la Ley de 17 de marzo de 2021, que introdujo un nuevo artículo, el 22ter, sobre los derechos de las personas en situación de discapacidad. En Francia se presentó el 20 de enero de 2021 en el registro de la Asamblea Nacional el Projet de loi constitutionnelle complétant l'article 1er de la Constitution et relatif à la préservation de l'environement. El 5 de julio de 2021 se produjo su modificación en décima lectura en el Senado. Desde el dossier de la Asamblea Nacional (https://www. assemblee-nationale.fr/dyn/15/dossiers/alt/pjlc_environnement) se puede seguir la tramitación y acceder a todas las publicaciones (entre otros, el dictamen del Consejo de Estado y el extenso informe de la Commission des lois constitutionnelles, de la législation et de l'administration et de l'administration générale de la République). En Bulgaria el 2 de septiembre de 2020 fue presentada una propuesta por parte de diputados de la Asamblea Nacional, que fracasó tres meses después al no lograr el apoyo parlamentario suficiente. El borrador fue examinado en detalle por la Comisión de Venecia en la opinión urgente y provisional de 11 de diciembre de 2020. También se puede consultar la Resolución del Parlamento Europeo, de 8 de octubre de 2020, sobre el Estado de Derecho y los derechos fundamentales en Bulgaria), En Italia la última reforma se realizó por la Legge Costituzionale 19 ottobre 2020, n. 1, que dispuso la modificación de los artículos 56, 57 y 59 de la Constitución en relación con el número de miembros de la Cámara de Diputados y del Senado.. La celebración del referéndum celebrado los días 20 y 21 de septiembre de 2020 puede consultarse desde la página Speciale Referendum costituzionale del Ministerio del Interior. En Islandia existen cuatro proyectos de reforma constitucional insertos en el proceso actual de reforma que pretendería completar el iniciado por el Althing en 2010. En Luxemburgo, el 15 de mayo se aprobó una Ley de reforma el artículo 95 ter de la Constitución, relativa a los efectos de las declaraciones de inconstitucionalidad en las sentencias del Tribunal Constituciona,. En Rusia, La Constitución fue reformada a través del Decreto n. ${ }^{\circ} 445$, de 3 de julio de 2020, que ordenaba la publicación oficial de la Constitución de la Federación Rusa con todas sus reformas. Previamente se había celebrado un referéndum, entre los días 25 de junio y 1 de julio. Se trata de una reforma de gran profundidad, que afecta a los principales órganos del Estado (especialmente al Consejo de Estado, la Duma, la Presidencia y el Tribunal Constitucional) y establece la supremacía de las leyes rusas sobre los tratados internacionales).

81 El Grupo Plural presentó la Proposición de Ley Orgánica de modificación de la Ley Orgánica 4/1981, de 1 de junio, de los estados de alarma, excepción y sitio, de la Ley Orgánica 3/1986, de 14 de abril, de Medidas Especiales en Materia de Salud Pública y de la Ley General de Sanidad. (122/000057). El Partido 
varios autores $^{82}$, parece apuntar dicha opción como posible solución. Esto se afirma sin duda desde la consciencia de las dificultades que entraña el procedimiento de reforma agravado, y más aún en el actual contexto de fragmentación y confrontación política. La reforma de la ley orgánica aparecería como solución para cubrir, dentro del estado de excepción, los supuestos de crisis sanitaria cuando las medidas del estado de alarma resulten insuficientes, y singularmente si se ha de adoptar del confinamiento domiciliario. No obstante, si se optase por esta vía de reforma únicamente de la LOEAES, persistiría el problema de la falta de cobertura de situaciones verdaderamente urgentes e inaplazables, y cuya solución ha de ser inmediata, puesto que el estado de excepción, sin una reforma constitucional, no podría declararse más que con autorización del Congreso, previa convocatoria y celebración de un pleno para su debate, eventual enmienda del real decreto y votación, lo que siempre supone una cierta demora en tiempo que, en ocasiones, puede resultar crucial para la resolución de la crisis. Y quizá también persistiría la duda de constitucionalidad de tal reforma de la ley orgánica que posibilitara el confinamiento domiciliario, por la afectación que supone del contenido esencial a la libertad deambulatoria del artículo $17 \mathrm{CE}$, cuando «se hace muy difícil pensar en el cumplimiento de todas las garantías judiciales correspondientes de un confinamiento masivo» ${ }^{83}$ que serían las mismas bajo un decreto de alarma y bajo un decreto de excepción. Máxime si se tiene en cuenta que el art. 55.1 de la Constitución "permite y no permite», simultáneamente, suspender bajo estado de excepción, el derecho del artículo 17, pues lo que nunca puede suspenderse son las garantías de información y asistencia letrada al detenido. Eso es un núcleo no disponible para el legislador orgánico, sino solo para el poder constituyente.

Por tanto, que pueda sugerirse como posible solución la reforma de la ley orgánica (lo que, dado el contexto español, seguramente sería la única solución posible en la práctica) no significa que sea lo más adecuado, si es que se quiere, como parece apuntar la praxis del estado de alarma hasta la fecha, flexibilizar el régimen de incidencia en los derechos fundamentales en vía de urgencia, con una intervención meramente gubernativa en una primera fase aunque sea precisa una ratificación parlamentaria posterior. Recuérdese que entre los argumentos que se han dado por parte del Gobierno para declarar un estado de alarma y no el de excepción (véanse las alegaciones del abogado del Estado en la STC de 14 de julio) figuraba singularmente el motivo de urgencia, de inaplazable necesidad de tomar

Popular presentó a finales de agosto de 2020 una proposición de ley de reforma de la LOAES. El Grupo Popular presentó una proposición de ley de reforma no de la LOEAES, sino de la Ley General de Sanidad, (122/000077 Proposición de Ley Orgánica de protección de la salud y de los derechos y libertades fundamentales, BOCG, CD, n. 106-17 de septiembre de 2021)

82 Cuenca Miranda, A., «Análisis crítico de un estado de alarma excepcional: la Covid-19 y el derecho de excepción», en GARrido López, C., Excepcionalidad y derecho: el estado de alarma en España, Fundación Manuel Giménez Abad, Zaragoza, pp. 295-323, 2021; Cotino Hueso, L., «La (in)constitucionalidad de las restricciones ...», op. cit., pp. 159-195.

83 Cotino Hueso, L., «La (in)constitucionalidad de las restricciones ...», op. cit., p. 169. 
medidas en el momento en que se tomaron, que no permitía, en su cualificada opinión, la demora que hubiera supuesto una convocatoria del Pleno del Congreso para el debate y votación de la autorización de un estado de excepción, cuestión que, como en su momento analicé, también jugó un importante papel en el estado de alarma que se declaró en 2010. Este problema solo podría solucionarse, con una reforma agravada de la Constitución ${ }^{84}$, que diese cobertura a una declaración, sin intervención parlamentaria, de un estado de emergencia por salud pública. Además, los estados excepcionales son un númerus clausus en una Constitución, como la nuestra, que ha optado por el modelo de mayor racionalidad en la regulación de los estados excepcionales, y hacer surgir de la nada, en vía de ley orgánica, un estado intermedio, podría resultar, al menos discutible desde la óptica de la introducción histórica de la figura en nuestro sistema en relación con los modelos de recepción del derecho de excepción en el constitucionalismo comparado.

Para terminar, han existido reformas constitucionales con motivo de la pandemia. Si bien en la mayoría de los países los debates todavía el desafío al sistema derivado de la crisis sanitaria por el coronavirus no se ha plasmado en reformas constitucionales, en algunos casos puede hacerlo pronto ${ }^{85}$ y existen dos Estados en los que sí se ha producido una reforma para hacer frente a la pandemia (o motivados por ella).

El primero es la República de Angola. La reforma partió de la propuesta del Presidente João Lourenço el 2 de marzo de 2021 y fue aprobada en el Parlamento el 22 de junio. Entre otras muchas modificaciones de la Constitución de 2010, se trata de una reforma que tiene por objeto conferir dignidad constitucional, mediante la introducción del artículo 58-A, a un nuevo tipo de estado excepcional —la «situación de calamidad pública»_, que se añade a (sin confundirse con) los ya regulados en el texto constitucional —estados de guerra, de sitio y de emergencia - todos los cuales permiten suspender derechos. La situación de calamidad pública se declara por el Presidente de la República y puede condicionar la posibilidad del ejercicio de los derechos fundamentales. Es una situación en la que las medidas necesarias para la recuperación de la normalidad precisan de una «invasión profunda» de los derechos, libertades y garantías. Por ello, se exige la audiencia, previa a esta declaración, de la Asamblea Nacional, por cuanto los derechos de los ciudadanos, durante su vigencia, vienen a ser restringidos de modo particularmente intenso. Sin embargo, el control parlamentario es menor en el momento de su prórroga, que compete exclusivamente al Presidente de la

84 Sieira Mucientes, S., «Los estados excepcionales», op. cit., pp. 361-393; Sieira Mucientes, S., «Estado de alarma», op. cit., pp. 275-305.

85 En Portugal, por ejemplo, parece probable que la cuestión vaya a plantearse en los trabajos de la Comisión Eventual para la Reforma Constitucional pero las pocas iniciativas presentadas hasta el momento no prevén una modificación del art. 138.En Japón, la aprobación de la ley sobre el referéndum el 11 de junio en el Parlamento, puede llevar a la primera reforma de la Constitución de 1946, en la que, entre otras medidas, se atribuirían más poderes excepcionales o de emergencia al Ejecutivo. 
República. En la exposición de motivos (II, 4) se justifica la introducción del nuevo estado excepcional por el hecho de que «la pandemia provocada por la COVID-19 ha venido a demostrar la existencia de una realidad para la cual la República de Angola no está preparada» ${ }^{86}$.

El segundo es el Estado de Pensilvania. La reforma de la Constitución de Pensilvania por la que se modifican el art. III, par. 9 y el art. IV, par. 20 (Disaster emergency declaration and management ${ }^{87}$ fue sometida a referéndum el 18 de mayo de $2021^{88}$, junto con las primarias municipales, y aprobada por el voto favorable del $53 \%$. Ha supuesto una nueva regulación del estado de emergencia y una limitación de los poderes del Gobernador, que no podrá decretarlo por un plazo superior a 21 días, salvo que sea ampliado por resolución concurrente del Senado y de la Cámara de Representantes. En resumen, ambas enmiendas constitucionales permiten al Gobernador, por su autoridad, aprobar preliminarmente, sin el concurso de ambas Cámaras, una orden ejecutiva o proclamación del estado de emergencia, en el supuesto de que se produzca una emergencia que amenace la vida, la salud y seguridad o el bienestar de la comunidad, ya sea una emergencia por causas

86 «Artículo 58. ${ }^{\circ}$-A (Situación de calamidad pública). 1. El ejercicio de los derechos, libertades y garantías de los ciudadanos puede ser condicionado en caso de situación de calamidad pública, en los términos de la Constitución y de la ley. 2. La situación de calamidad pública se declara por el Presidente de la República oída la Asamblea Nacional. 3. Una ley definirá los casos que pueden dar lugar a la declaración de la situación de calamidad pública».

$87 \S 20$. Disaster emergency declaration and management. (a) A disaster emergency declaration may be declared by executive order or proclamation of the Governor upon finding that a disaster has occurred or that the occurrence or threat of a disaster is imminent that threatens the health, safety or welfare of this Commonwealth. (b) Each disaster emergency declaration issued by the Governor under subsection (a) shall indicate the nature, each area threatened and the conditions of the disaster, including whether the disaster is a natural disaster, military emergency, public health emergency, technological disaster or other general emergency, as defined by statute. The General Assembly shall, by statute, provide for the manner in which each type of disaster enumerated under this subsection shall be managed.(c) A disaster emergency declaration under subsection (a) shall be in effect for no more than twenty-one (21) days, unless otherwise extended in whole or part by concurrent resolution of the General Assembly.(d) Upon the expiration of a disaster emergency declaration under subsection (a), the Governor may not issue a new disaster emergency declaration based upon the same or substantially similar facts and circumstances without the passage of a concurrent resolution of the General Assembly expressly approving the new disaster emergency declaration. En relación con esta modificación, también se produjo la del: $§ 9$. Action on concurrent orders and resolutions. Every order, resolution or vote, to which the concurrence of both Houses may be necessary, except on the questions of adjournment or termination or extension of a disaster emergency declaration as declared by an executive order or proclamation, or portion of a disaster emergency declaration as declared by an executive order or proclamation, shall be presented to the Governor and before it shall take effect be approved by him, or being disapproved, shall be repassed by two-thirds of both Houses according to the rules and limitations prescribed in case of a bill.

88 El texto de la pregunta en el referéndum fue el siguiente: ¿Se debería enmendar la Constitución de Pensilvania de manera que se modifique la ley existente a fin de que: una declaración de emergencia por desastre venza automáticamente después de 21 días, sin importar la gravedad de la emergencia, a menos que la Asamblea General tome medidas para extender la emergencia por desastre; el Gobernador no pueda declarar una nueva emergencia por desastre para responder a los peligros que el Commonwealth enfrente a menos que la Asamblea General apruebe una resolución simultánea; la Asamblea General promulgue nuevas leyes para el manejo de desastres? (https://www.dos.pa.gov/VotingElections/Pages/Joint-Resolution-2021-1-Espanol.aspx) 
naturales, militares, de salud pública, tecnológica u otro tipo de emergencia natural definida por la ley. Corresponde a la Asamblea General legislar, mediante leyes especiales, sobre el modo en que cada tipo de emergencia debe ser gestionado y las medidas que corresponde tomar para su resolución.

Lo que es verdaderamente diferencial, en relación con la garantía de los derechos, es que la declaración por parte del Gobernador puede estar en vigor un máximo de 21 días, a menos que, si se desea su prórroga, cuente con la aprobación del Parlamento, sabiendo que, además, esta aprobación se exceptúa de la regla general de aprobación por los dos tercios de cada Cámara contenida en el artículo III párrafo 9 (basta una mayoría simple); y que tras la expiración de un estado de emergencia, el gobernador no podrá volver a declararlo, bajo el mismo supuesto de hecho, a menos que cuente con la autorización de la Asamblea General (con la misma regla de mayorías).

El procedimiento de reforma de la Constitución de Pensilvania sirve como extraordinario término de comparación para España pues se trató de un procedimiento parangonable al exigido para una reforma agravada de nuestra Constitución por mayoría cualificada en cada Cámara y referéndum de reforma que se hizo coincidir, oportunamente, con un proceso electoral. Además, contempla una vía de urgencia, del todo conveniente para que el ejecutivo disponga de un amplio margen de maniobra en relación con la intensa limitación de los derechos que la resolución de la crisis puede comportar, sin perjuicio de la necesaria ratificación o derogación de las medidas por el parlamento en un corto plazo de tiempo.

\section{CONCLUSIONES}

La pandemia del Covid ha supuesto una crisis social y económica de proporciones globales, $y$, por tanto, un reto que los ordenamientos se han visto obligados a resolver utilizando fórmulas que no podían encuadrase plenamente en las previsiones del derecho constitucional de excepción allí donde existe, lo que ha significado un alejamiento de las previsiones constitucionales (mutación o quiebra) en dos frentes principales, a saber: alteración de los sistemas de fuentes del derecho e imposición de limitaciones particularmente intensas de los derechos fundamentales, que, según el concepto que se maneje de «suspensión» han supuesto auténticas suspensiones de los mismos, por vías extraconstitucionales, que posteriormente han quedado incorporadas a la narrativa política o jurídica, según los casos, bien por su pacífica práctica, incontestada en el control de constitucionalidad, o bien mediante una interpretación de los Tribunales Constitucionales, que ha servido de base, precisamente, cuando se ha dado, a la mencionada mutación constitucional. Adicionalmente, en algunos casos, se ha sumado la crítica por reducirse el margen de control que ha quedado al Parlamento sobre la duración y extensión de las medidas. Por otra parte, los Estados que no poseen un derecho constitucional de excepción, tampoco se han visto exentos de crítica, básicamente en los mismos frentes. 
Como señala ROLLNERT ${ }^{89}$ tanto la mutación como la quiebra constitucionales desafían las bases de la Teoría de la Constitución. Si la mutación constitucional es consecuencia de que el Tribunal Constitucional, en su condición de intérprete supremo en realidad reforma o transmuta la norma en otra diferente, sus críticos le acusarán de operar una mutación constitucional usurpando las funciones del constituyente. No ha sido este, afortunadamente, el caso del Tribunal Constitucional español que, con su STC de 14 de julio, ha venido a poner fin a una década de praxis del estado de alarma que debe calificarse de mutación constitucional (en el sentido que le da Hsü Dau Lin a las actuaciones políticas contra Constitutionem, que se hubieran consagrado, de no mediar esta Sentencia, como mutaciones del texto mediante la invocación del consenso social y del maleable concepto de «Constitución viviente»). El problema de ambos tipos de mutación constitucional, sea mediante la interpretación o la praxis contra constitutionem, es que suponen, en realidad, una suplantación del genuino soberano — emparentada analógicamente con la categoría de Schmitt de la destrucción de la Constitucióny, respectivamente, un falseamiento o una violación de la Constitución. Por ello es del todo conveniente en esta materia dejar ser soberano al poder constituyente.

Efectivamente, hemos sostenido aquí que, hasta la STC de 14 de julio de 2021, la praxis del estado de alarma ha constituido una mutación constitucional. Se ha utilizado, tanto en 2010 como en 2020, como expediente de cobertura de una actuación necesariamente urgente e inaplazable al que el Gobierno ha podido acudir por la simplicidad de su procedimiento inicial (que no tienen los estados de excepción ni de sitio). Y esto ha ocurrido porque nuestra Constitución no prevé en el derecho de excepción una vía de urgencia, que sí ha existido tradicionalmente en nuestro constitucionalismo histórico (Constituciones de 1869 y 1931) y que permitía al Gobierno la suspensión de garantías, bajo su exclusiva responsabilidad, debiendo el Parlamento, posteriormente, resolver sobre dicha suspensión. A este respecto, la Constitución de 1931 añadía una garantía adicional, la obligación de convocar al Parlamento en un plazo de ocho días, o, en su defecto, su convocatoria automática al noveno ${ }^{90}$.

La misma conclusión apunta el análisis del concepto de suspensión de los derechos fundamentales, que existe cuando no ha lugar a la apreciación judicial de la proporcionalidad de unas medidas impuestas con carácter general, como ya sucedió en el estado de alarma declarado en 2010, y de modo notoriamente mucho más extenso en 2020, comportando severas restricciones de los derechos fundamentales, como ha señalado el TC en su Sentencia de 14 de julio, y esto ha contribuido a desdibujar, más aún, los perfiles de una figura, el estado de alarma, de infrecuente mención en el constitucionalismo comparado y cuya introducción en la Constitución española resultó

89 Rollnert Liern, G., «La mutación constitucional, entre la interpretación y la jurisdicción constitucional», REDC, n. ${ }^{\circ} 101,2014$, pp. 125-155; concretamente, pp. 151-152.

90 Sieira Mucientes, S., «Los estados excepcionales», op. cit.; concretamente, pp. 390-391. 
discutida desde el primer momento. Es imprescindible, por imperativo democrático, que el derecho de excepción tenga una configuración correcta que estimule su cumplimiento, para que no se resienta, en situaciones de crisis, el edificio constitucional, basado en dos pilares esenciales, separación de poderes y garantía de los derechos.

Sería indicado, además, como he sostenido, si se optase por la recuperación en el texto constitucional de un nuevo estado excepcional, un replanteamiento de su nomen iuris, reconduciendo los actuales estados de alarma y excepción (al fin y al cabo, la praxis se ha decantado por ofrecer algo aproximado a una mezcolanza entre ambas figuras) al que podría denominarse «estado de emergencia», expresión generalizada en el constitucionalismo comparado ${ }^{91}$, y que puede resultar, valga la expresión, menos «alarmante» para la opinión pública, que las denominaciones «estado de alarma»y «estado de excepción», para hacer frente a los supuestos de hecho que actualmente constituyen el sustrato de la declaración de los estados de alarma y excepción, incluyéndose, especialmente, las crisis sanitarias, pudiéndose reservar a una ley individualizada para el caso concreto la gestión de la crisis, lo que ahorraría no pocas discordancias entre los órganos jurisdiccionales que se han producido por dejar la intervención en los derechos en manos de las Comunidades Autónomas en aplicación de la legislación sanitaria de emergencia y que pudiera comportar, con su mención en el artículo 55.1 en relación con los artículos 17 y 116 de la Constitución, una suspensión general de los derechos fundamentales indicados, incluso, singularmente, el derecho a la libertad y a la seguridad, con la necesaria convalidación parlamentaria posterior de las medidas en un plazo breve de tiempo, en todo caso, a nuestro parecer, sensiblemente menor que el establecido para la convalidación de los decretos-leyes - los cuales no pueden, por su propia naturaleza, incidir en el contenido esencial de los derechos fundamentales-. Hay que advertir que la reforma constitucional, en este caso, sería la prevista en el artículo 168, reforma agravada, puesto que tendría incidencia en la sección primera del Capítulo segundo del Título I (derechos fundamentales) al regular la suspensión general de los mismos. Solución que ya apunté en su momento y que, matizadamente se podría afirmar que no está lejos, ni material ni procedimentalmente, de la que se ha aprobado en fechas recientes en el Estado de Pensilvania, de emblemática memoria para el constitucionalismo histórico.

$$
* * *
$$

TiTLE: Coronavirus State of Emergency as an Emerging state of Exception: Mutation or Constitutional Reform?

ABSTRACT: States have found it necessary to respond urgently to the coronavirus crisis by applying their constitutional and legal frameworks well aware, however, that the solutions offered would not fit entirely

91 Compilación sobre los estados de emergencia de la Comisión de Venecia del Consejo de Europa de 16 de abril de 2020 . 
within the categories of emergency law in relation to the hierarchy of laws, decrees and other administrative regulations and the consequent guarantee of fundamental rights and freedoms. This has led to unconfessed changes in their constitutions (constitutional mutations) by means of consensual practices that have not yet been subjected to constitutional control or by the interpretation of the constitutional courts that has led precisely to such mutations. The latter has fortunately not been the case in Spain. The Spanish Constitutional Court has established in its recent judgment of 14 July 2021 that the state of alarm does not provide sufficient cover for the limitations of fundamental rights, especially with regard to the confinement imposed on citizens, which has meant a general suspension of the right to freedom of movement rather than just a limitation of the same. Therefore, the Spanish government should have declared a state of exception, which only requires a simple majority for its approval in Congress. The Spanish Government has justified that the declaration of a state of alarm was the only way to face the crisis due to the compelling need to adopt urgent measures, since the state of exception needs the prior consent of Congress. The best solution to this constitutional challenge, according to this study, is the reform of the Spanish constitution by creating a new state of emergency, an intermediate figure between the state of alarm and the state of exception, which provides the government with a means of urgency, requiring parliamentary ratification after a short period of time, similar to that which existed under the provisions of the 1931 Spanish Constitution. However, this would imply an aggravated constitutional reform whose procedure is particularly complex both legally and politically in Spain. In this respect, very few constitutions in the world have been reformed due to the coronavirus crisis, but the Pennsylvania constitution is an excellent reference for the Spanish constitutional system both in terms of content and procedure.

RESUMEN: La gran mayoría de los países han tenido que responder jurídicamente a la emergencia de salud pública por coronavirus declarado pandemia mundial en 2020 y a la subsiguiente crisis sanitaria, social y económica, sin precedentes, mediante transformaciones inconfesadas (auténticas mutaciones) de sus ordenamientos constitucionales, fortaleciendo el poder ejecutivo y debilitando correlativamente al parlamento, alterando por vias extraconstitucionales sus sistemas de fuentes del derecho e imponiendo limitaciones particularmente intensas, cuando no verdaderas suspensiones, según se entienda este concepto, de los derechos fundamentales, que posteriormente pueden quedar incorporadas a la normativa constitucional, bien por su pacífica práctica, incontestada en el control de constitucionalidad, o bien mediante una interpretación de los Tribunales Constitucionales, praeter o contra constitutionem, que puede servir de base a la mencionada mutación constitucional. España es uno de los Estados en que el Tribunal constitucional se ba pronunciado con mayor premura sobre esta cuestión, acabando con años de praxis de mutación constitucional respecto del estado de alarma y consagrando la necesidad de utilizar el estado de excepción para suspender derechos fundamentales en los estrictos términos de los artículos 116 en relación con el 55.1 de la Constitución. Todavía pocos Estados han seguido la deseable vía de la reforma constitucional para dar cabida a este tipo de emergencia de salud pública, que, según el parecer de los expertos, no será la última vez que se presente, y podría no tardar en reiterarse. En este artículo se efectúa un recorrido por las diversas soluciones adoptadas en derecho comparado, señalando las mutaciones de la Constitución que se están operando, para acabar deteniéndose, con brevedad, en lo acontecido en España y sugerir un esbozo de reforma constitucional, conveniente, a todas luces, en esta cuestión nuclear a la democracia constitucional.

KEY WORDS: coronavirus, COVID, comparative law, state of alarm, state of exception, state of emergency, right of exception, constitutional mutation, reform of the constitution, suspension of fundamental rights and freedoms, limitations of fundamental rights and freedoms.

PALABRAS Clave: alarma, excepción, COVID, coronavirus, suspensión, derechos fundamentales, reforma, mutación, Constitución, derecho comparado.

FECHA DE RECEPCIÓN: 26.07.2021

FECHA DE ACEPTACIÓN: 20.09.2021 
